Atmos. Chem. Phys., 19, 13891-13910, 2019

https://doi.org/10.5194/acp-19-13891-2019

(C) Author(s) 2019. This work is distributed under

the Creative Commons Attribution 4.0 License.

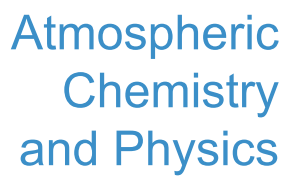

(c) (i)

\title{
Global nighttime atomic oxygen abundances from GOMOS hydroxyl airglow measurements in the mesopause region
}

\author{
Qiuyu Chen ${ }^{1,2}$, Martin Kaufmann ${ }^{1,2}$, Yajun Zhu ${ }^{1,3}$, Jilin Liu ${ }^{1,2}$, Ralf Koppmann ${ }^{2}$, and Martin Riese ${ }^{1,2}$ \\ ${ }^{1}$ Institute for Energy and Climate Research, Forschungszentrum Jülich, Jülich, Germany \\ ${ }^{2}$ Institute for Atmospheric and Environmental Research, University of Wuppertal, Wuppertal, Germany \\ ${ }^{3}$ State Key Laboratory of Space Weather, National Space Science Center, Chinese Academy of Sciences, Beijing, China
}

Correspondence: Yajun Zhu (y.zhu@swl.ac.cn)

Received: 30 April 2019 - Discussion started: 13 May 2019

Revised: 17 September 2019 - Accepted: 18 October 2019 - Published: 19 November 2019

\begin{abstract}
This paper presents a new dataset of nighttime atomic oxygen density $[\mathrm{O}]$, derived from $\mathrm{OH}(8-4)$ rovibrational band emissions, using a non-local thermal equilibrium model, with the aim of offering new insight into the atomic oxygen abundances in the mesopause region. The dataset is derived from the level-1 atmospheric background measurements observed by the Global Ozone Monitoring by Occultation of Stars (GOMOS) instrument aboard Envisat, with the Sounding of the Atmosphere using Broadband Emission Radiometry (SABER) measurements for the atmospheric background. Raw data are reprocessed into monthly zonal mean values in $10^{\circ}$ latitude bins with a fixed altitude grid of $3 \mathrm{~km}$. The dataset spans from $70^{\circ} \mathrm{S}$ to $70^{\circ} \mathrm{N}$ in latitude and from 80 to $100 \mathrm{~km}$ in altitude, covering a time period from May 2002 to December 2011 at local times from 22:00 to 00:00 LT.

The atomic oxygen density peaks at about $95 \mathrm{~km}$ and the highest values are in the range of 3-8 $\times 10^{11}$ atoms cm${ }^{-3}$, depending on latitude and season. There is a rapid decrease of [O] below the peak. The annual oscillation (AO), semiannual oscillation (SAO) and the solar cycle impact are distinguished from the $[\mathrm{O}]$ longtime series variations. This new GOMOS [O] dataset conforms to other published datasets and is consistent with the $[\mathrm{O}]$ datasets obtained from the Scanning Imaging Absorption Spectrometer for Atmospheric CHartographY (SCIAMACHY) OH airglow measurements within about $\pm 20 \%$.
\end{abstract}

\section{Introduction}

In the middle and upper atmosphere, atomic oxygen $(\mathrm{O})$ is mainly produced by the photolysis of molecular oxygen and ozone, and transported downward by diffusion and mixing from the thermosphere to the mesopause. Its lifetime varies from over 1 week at $100 \mathrm{~km}$ to around $1 \mathrm{~d}$ at $80 \mathrm{~km}$ due to its increasing chemical loss rate with decreasing altitude (Brasseur and Solomon, 2005). Atomic oxygen is one of the most abundant reactive trace species in the upper mesosphere/lower thermosphere (MLT) region and plays a crucial role in the photochemical equilibrium and energy balance of this region. Most exothermic chemical reactions, which heat the MLT region, are associated with atomic oxygen (Brasseur and Offermann, 1986; Riese et al., 1994; Mlynczak et al., 2013c). The collisions between $O$ and infrared-active greenhouse gases like $\mathrm{CO}_{2}$ also predominantly lead to radiative cooling in this region (Mlynczak et al., 2013a).

The measurement of atomic oxygen dates back to before the satellite era when the MLT region was explored by means of sounding rocket experiments, hosting resonance fluorescence instruments or mass spectrometers (e.g., Dickinson et al., 1974, 1980; Sharp, 1980; Offermann et al., 1981; Sharp, 1991). They are capable of providing direct in situ measurements of atomic oxygen, although it is difficult to obtain a consistent global picture of absolute density values from these measurements, which differ by a factor of more than 40 (Offermann et al., 1981; Sharp, 1991).

However, these measurements lead to the development of photochemical models of the Earth's day- and nightglow, which enables the use of proxies of the atomic oxygen abundance obtained from satellite observations. Suitable prox- 
ies are airglow emissions (e.g., $\left.\mathrm{OH}^{*}, \mathrm{O}_{2}^{*}, \mathrm{O}\left({ }^{1} \mathrm{~S}\right)\right)$ and thermal emissions (e.g., $\mathrm{O}_{3}$ at $9.6 \mu \mathrm{m}$ ), in combination with corresponding photochemical models. The hydroxyl $(\mathrm{OH})$ airglow emissions are associated with the spontaneous radiative transitions of excited $\mathrm{OH}^{*}$ radicals. These $\mathrm{OH}^{*}$ radicals are mainly produced by the chemical reaction of ozone with atomic hydrogen. Highly excited molecular oxygen $\left(\mathrm{O}_{2}^{*}\right)$ in a metastable state is generated from atomic oxygen recombination and can be de-excited by $\mathrm{O}$ or $\mathrm{O}_{2}$, while the $\mathrm{O}\left({ }^{1} \mathrm{~S}\right)$ and $\mathrm{O}_{2}$ A-band emissions are radiated from the products. These airglow emissions rely on the atomic oxygen recombination or ozone destruction and can be recognized as a kind of chemical afterglow. Therefore, they are frequently used as a proxy to retrieve atomic oxygen.

More recent measurements were conducted by the Sounding of the Atmosphere using Broadband Emission Radiometry (SABER) instrument on the Thermosphere-IonosphereMesosphere Energetics and Dynamics (TIMED) satellite. The instrument detects $\mathrm{OH}^{*}$ nightglow radiances at 2.0 and $1.6 \mu \mathrm{m}$ as well as $\mathrm{O}_{3}$ thermal emissions at $9.6 \mu \mathrm{m}$ (Smith et al., 2010; Mlynczak et al., 2013b, 2018; Panka et al., 2018). The Scanning Imaging Absorption Spectrometer for Atmospheric CHartographY (SCIAMACHY) instrument on the European Environmental Satellite (Envisat) measures the $\mathrm{O}\left({ }^{1} \mathrm{~S}\right)$ green line at $557.7 \mathrm{~nm}$ and a broad range of $\mathrm{OH}^{*}$ airglow emissions (Kaufmann et al., 2014; Lednyts'kyy et al., 2015; Zhu et al., 2015; Zhu and Kaufmann, 2018). The Optical Spectrograph and Infrared Imager System (OSIRIS) instrument on the Odin satellite probes the $\mathrm{O}_{2} \mathrm{~A}$ band at $762 \mathrm{~nm}$ and $\mathrm{OH}^{*}$ airglow at $725-745 \mathrm{~nm}$ and 770-815 nm (Sheese et al., 2011, 2014). During the period of 1991-1995, the Wind Imaging Interferometer (WINDII) instrument aboard the Upper Atmosphere Research Satellite (UARS) also observed the $\mathrm{O}\left({ }^{1} \mathrm{~S}\right)$ green-line and $\mathrm{OH}(8-3)$ band emissions at $734 \mathrm{~nm}$ (Russell and Lowe, 2003; Russell et al., 2005). Other instruments include the high-resolution Doppler imager (HRDI) aboard UARS, which also observes $\mathrm{O}_{2}$ A-band emissions (Hays et al., 1993); the Imager of Sprites and Upper Atmospheric Lightning (ISUAL) instrument aboard the FORMOSAT-2 satellite, which detects the $\mathrm{O}\left({ }^{1} \mathrm{~S}\right)$ green-line emissions (Gao et al., 2012); and the Solar Mesosphere Explorer (SME) spacecraft, which measures the $\mathrm{OH}(7-5)$ band emission at $1.87 \mu \mathrm{m}$ (Thomas, 1990).

While various datasets are consistent in terms of the overall profile shape of derived [O] densities, some discrepancies still exist (Mlynczak et al., 2013a, b, c, 2018; Kaufmann et al., 2014; Zhu and Kaufmann, 2018; Panka et al., 2018). The radiometric calibration of the instruments or differences in airglow model parameters are potential reasons. Therefore, no common consensus has generally been reached with regard to these aspects. Some new findings on airglow relaxation modeling and reaction kinetic parameters were recently published. A new pathway, in which highly vibrationally excited $\mathrm{OH}$ radicals $(v \geq 5)$ are deactivated by atomic oxygen to a lower state $\left(0 \leq v^{\prime} \leq v-5\right)$, is proposed and discussed
(Sharma et al., 2015; Kalogerakis et al., 2016; Panka et al., 2017, 2018; Fytterer et al., 2019; Kalogerakis, 2019). These results complicate the topic further.

To contribute another piece of information to the currently ongoing discussions, a new dataset derived from the $\mathrm{OH}$ nightglow observed by the Global Ozone Monitoring by Occultation of Stars (GOMOS) instrument on the European Space Agency (ESA)'s environmental satellite (Envisat) during the years 2002 to 2012 is presented and discussed here. This dataset is particularly valuable in that it was obtained at the same time as the already-published SABER and SCIAMACHY data but from a different instrument with its own radiometric calibration. Emissions from $\mathrm{OH}(8-4)$ are used to obtain atomic oxygen abundances, which is a similar proxy to that provided by the SABER and SCIAMACHY OH measurements.

This paper is structured as follows: the second section provides a brief introduction to the instrument and data processing procedure, followed by a section describing the airglow modeling. The derived results are shown in the fourth section, including error analysis as well as latitudinal and temporal analysis. The next section investigates the validation of the dataset in a broad context, including comparisons with the SCIAMACHY dataset and other data sources, while the final section concludes the topic with an outlook on future expectations.

\section{Measurements and data preparation}

\subsection{GOMOS on Envisat}

The GOMOS spectrometer is one of nine instruments aboard Envisat. It is designed to monitor ozone profiles and other trace species using stellar occultation and atmospheric transmission measurements in limb-viewing mode (ESA, 2010). Envisat follows a Sun-synchronous orbit with an Equator crossing time (descending node) of 22:00 LT (Gottwald et al., 2011). The operation period of GOMOS dates from April 2002 to April 2012. However, there was an instrument malfunction in summer 2005, resulting in a data gap of nearly 3 months. The GOMOS instrument delivers one vertical profile of measurements for each occultation, and the altitude coverage spans from 5 to $150 \mathrm{~km}$, with a vertical sampling rate of better than $2 \mathrm{~km}$ (Kyrölä et al., 2012). It has four spectral channels in the ultraviolet to near-infrared spectral range. The spectrometer B2 (SPB2), which provides the data used in this work, covers $925-955 \mathrm{~nm}$ with a spectral resolution of $0.13 \mathrm{~nm}$ at full width half maximum (FWHM) and a sampling step of $0.056 \mathrm{~nm}$ (Massimo Cardaci and Lannone, 2012). The GOMOS detector has three parallel bands. The central band probes the star spectra and the upper/lower bands record the atmospheric background radiation as calibration information, as indicated in Fig. 1. The altitudes of tangent points observed by three bands differ roughly by 


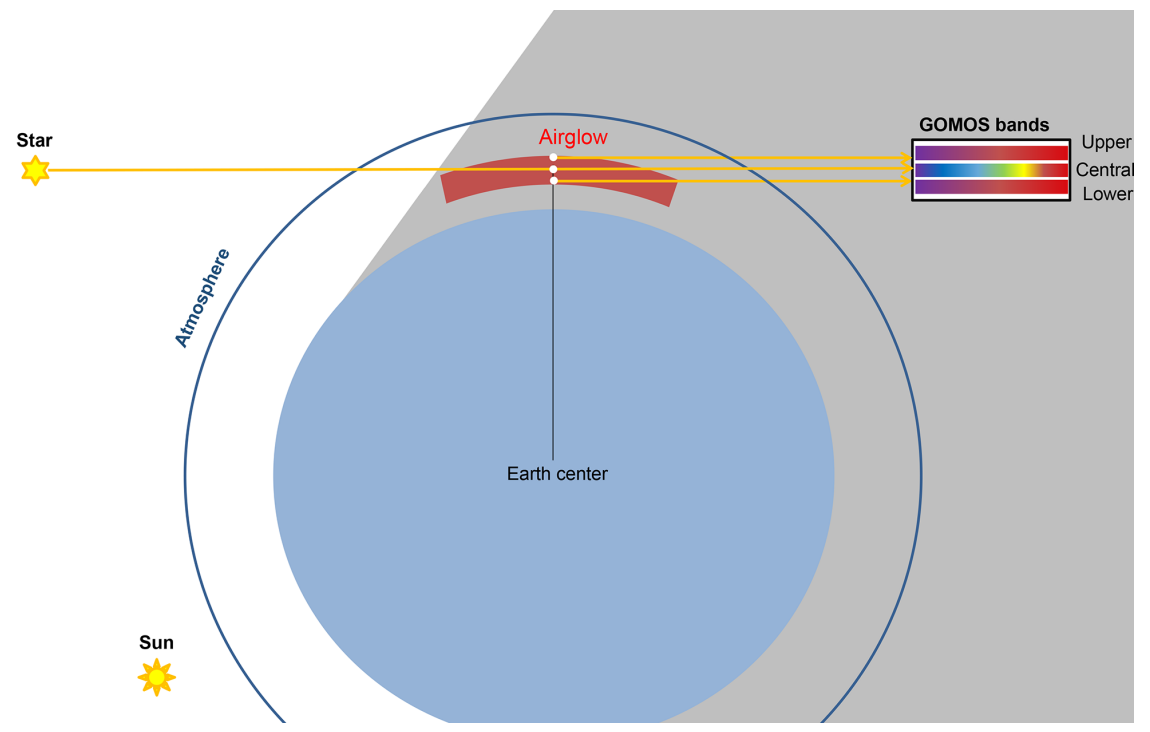

Figure 1. Schematic view of the GOMOS stellar occultation observations. The star transmission spectra are recorded in the central band of the instrument detector, while the atmospheric background radiation is imprinted in the upper/lower bands. The $\mathrm{O}_{2} \mathrm{~A}-\mathrm{band}$ and $\mathrm{OH}$ airglow emissions are detected in the limb observations. For each star spectrum, one upper and one lower spectrum are recorded simultaneously.

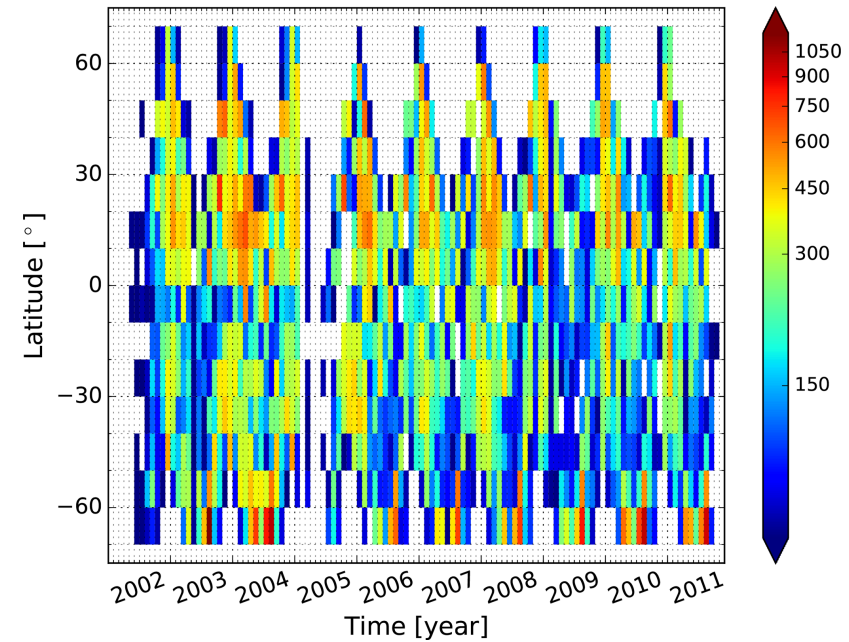

Figure 2. Latitudinal distribution of resampled GOMOS data available from 2002 to 2012. Color coding indicates the number of selected profiles for each monthly and zonally averaged $10^{\circ}$ latitude bin.

$1.7 \mathrm{~km} . \mathrm{OH}$ and $\mathrm{O}_{2}$ A band are regularly detected in the upper/lower bands, together with auroral emissions and the stray light scattered by particles or molecules in the atmosphere. This dataset, which is used in our analysis, is archived in the level-1b limb dataset but not directly utilized in the operational level- 2 data retrieval routines. The first analyses of the extracted $\mathrm{OH}$ and $\mathrm{O}_{2}$ A-band nightglow measurements from these background datasets were reported by Bellisario et al. (2014).

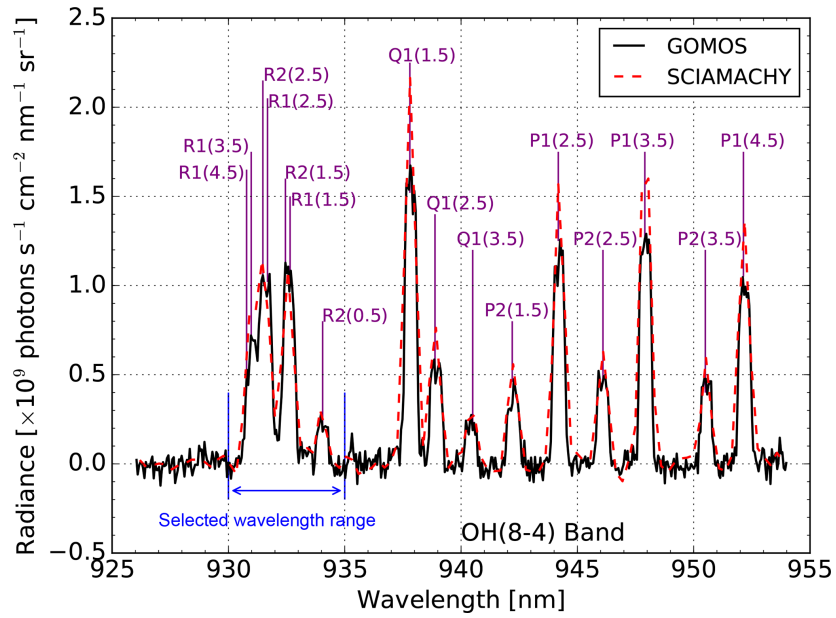

Figure 3. Monthly averaged spectrum from GOMOS (black solid line) for February 2004 at $40-50^{\circ} \mathrm{N}$ and at a tangent altitude of $89.5 \mathrm{~km}$. Strong emission lines from the $\mathrm{OH}(8-4)$ band are annotated with the branch and rotational quantum numbers. The wavelength range from 930 to $935 \mathrm{~nm}$ is selected and used in the retrieval. The corresponding SCIAMACHY data (red dashed line) are also given here for comparison.

\subsection{Data selection and resampling}

The GOMOS data were processed with the processor version 6.01-2012. The resulting level-1b limb products have already been geolocated and calibrated (Massimo Cardaci and Lannone, 2012). The signal-to-noise ratio (SNR) of single spectra is of the order of 1 , and the averaging of data is required for further processing of the data. 

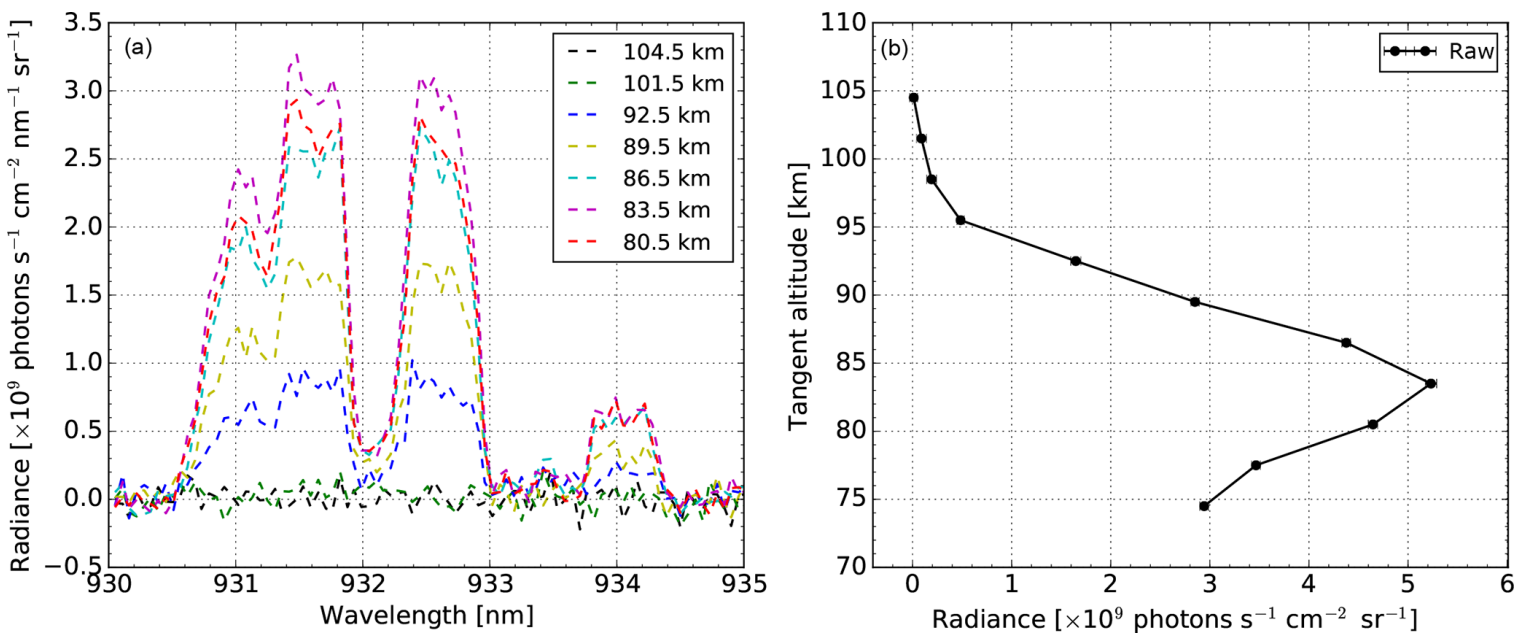

Figure 4. (a) GOMOS monthly zonal mean spectra of $\mathrm{OH}(8-4)$ emissions at tangent altitudes as given in the figure legend for October 2003 at $0-10^{\circ} \mathrm{S}$ and at a local time of 22:00-00:00 LT. (b) The spectrally integrated radiance over 930-935 nm versus tangent altitude for the same conditions. The error bars indicate the measurement noise for integrated radiance (see text).

The raw data from level- $1 \mathrm{~b}$ limb products are first filtered with the corresponding auxiliary "quality flag" and "product confidence data"(PCD), which indicate the presence of bad pixels, saturation, cosmic rays, modulation, dark current, flatfield or vignetting correction, with only data in the normal status being kept. This is then followed by a geolocationrelated selection, in which the data with ray-tracing errors are eliminated, and their star IDs and geolocation errors are restricted to within an acceptable range, as recommended by Dehn (2012). The stray light entering the field of view (FOV) of the instrument affects the illumination of the spectrometer and enhances the background noise. The stray light is characterized by the illumination flags and solar zenith angle (SZA) of satellite and tangent points, which are geometrically computed. The illumination conditions of GOMOS measurements are categorized into five flags (Kyrölä et al., 2010; van Gijsel et al., 2010), and the "bright limb" flag thereof is excluded in this work. SZA $>108^{\circ}$ is also applied as selection criteria. Near-infrared aurora at wavelengths of around 939 and $947 \mathrm{~nm}$, originating from the atomic nitrogen (N I) emissions and $\mathrm{N}_{2}^{+}$Meinel (2-1) band (Baker et al., 1977) are in the spectral range of SPB2. Observations in polar regions are therefore not considered in our analysis.

Due to the nature of the stellar occultation observations, the tangent points of single vertical profiles diverge significantly and are not stationary in latitude-longitude locations. In the level-2 product, they are characterized by the obliquity (Kyrölä et al., 2010), which is not available in the level$1 \mathrm{~b}$ data. Therefore, in this work, the latitude spread of tangent points is used instead and profiles with $>4^{\circ}$ deviation in tangent point latitudes are disregarded to ensure that every selected profile spans a geographical area of within $\pm 5^{\circ}$ latitude.
The archived level- $1 \mathrm{~b}$ data are signals recorded by the detector, which must be dynamically decoded to electrons and then converted to a physical unit of flux with wavelengthspecific radiometric calibration factors. The star is a point source, and part of the stellar light is spread to the lower and upper bands, which is supposed to be totally imaged in the central band in an ideal case. Considering the contamination of star leakage and residual stray light, which are assumed to be constant with altitude, the averaged spectra from above $110 \mathrm{~km}$ are subtracted from each profile as background radiation. No airglow emissions are found above the region of $110 \mathrm{~km}$ in the GOMOS measurements. The subtraction is then followed by the individual "base" removal at each altitude layer, in which this "base" offset is the mean of residual noise of the emission lines. The processed data are resampled into monthly and zonally averaged $10^{\circ}$ latitude bins with a fixed altitude grid of $3 \mathrm{~km}$ to enhance the spectra SNR and improve retrieval quality. The number of profiles selected for one sample bin (shown in Fig. 2) is around 100 to 300. In order to eliminate the effect of random and systematic noise as well as outliers while retaining as many profiles as possible, the largest and smallest $1 \%$ values are disregarded from the measurements at each sample bin.

Barrot et al. (2003) reported high pixel response nonuniformity (PRNU) variation of around $12 \%$ in spectrometer B (SPB). As shown in Fig. 3, in the spectral range of our interest (SPB2), we found the GOMOS data show a good agreement with the SCIAMACHY data at the spectral range of 930-935 nm, whereas the GOMOS radiances at the wavelength range of $935-955 \mathrm{~nm}$ are always $25 \%-30 \%$ lower compared to the SCIAMACHY measurements, which is not understood (Erkki Kyrölä, personal communication, 2019). Therefore, of the entire spectral range, only the wavelength region of $930-935 \mathrm{~nm}$ is utilized in the retrieval to derive the 

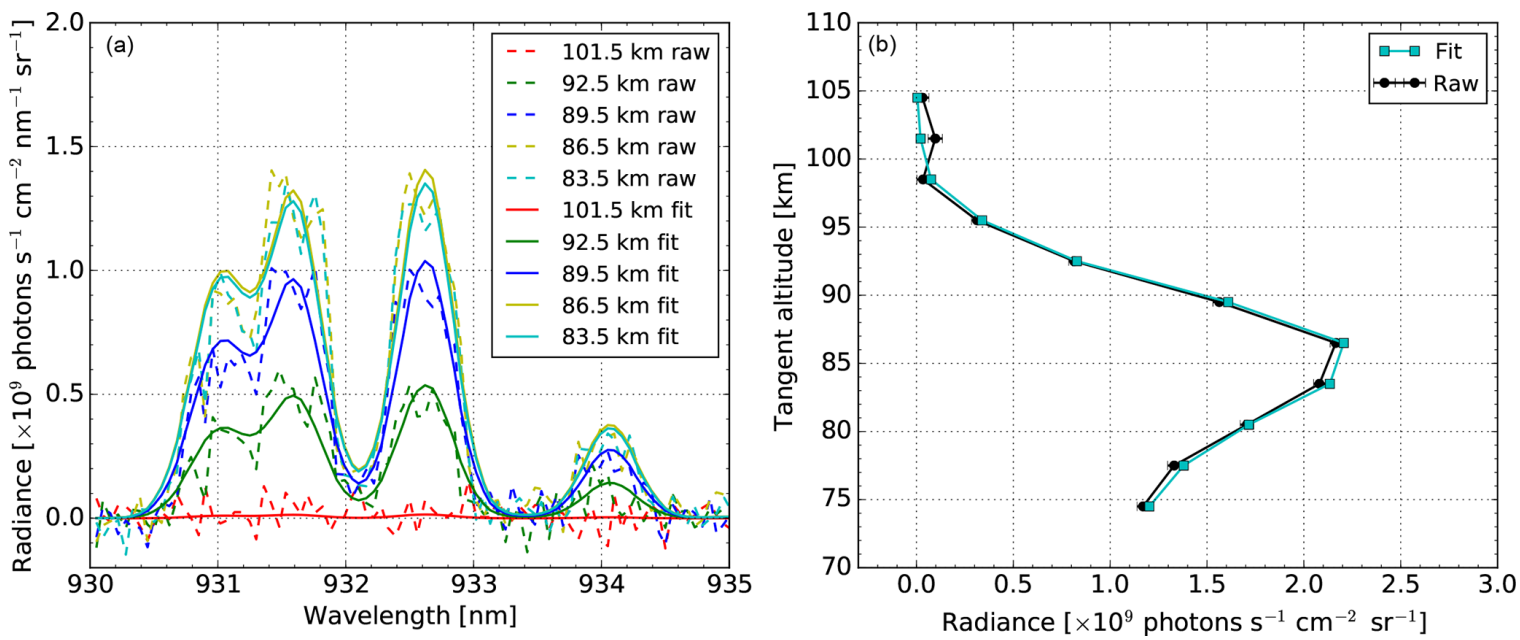

Figure 5. (a) Simulated spectra (fit, solid line) and measurements (raw, dashed line) of GOMOS monthly zonal mean measurements of $\mathrm{OH}(8-4)$ airglow emissions at tangent altitudes, as given in the figure legend for August 2003 at 30-40 ${ }^{\circ} \mathrm{S}$ and a local time of 22:00-00:00 LT. (b) The spectrally integrated radiance over 930-935 nm versus tangent altitude for the same conditions.

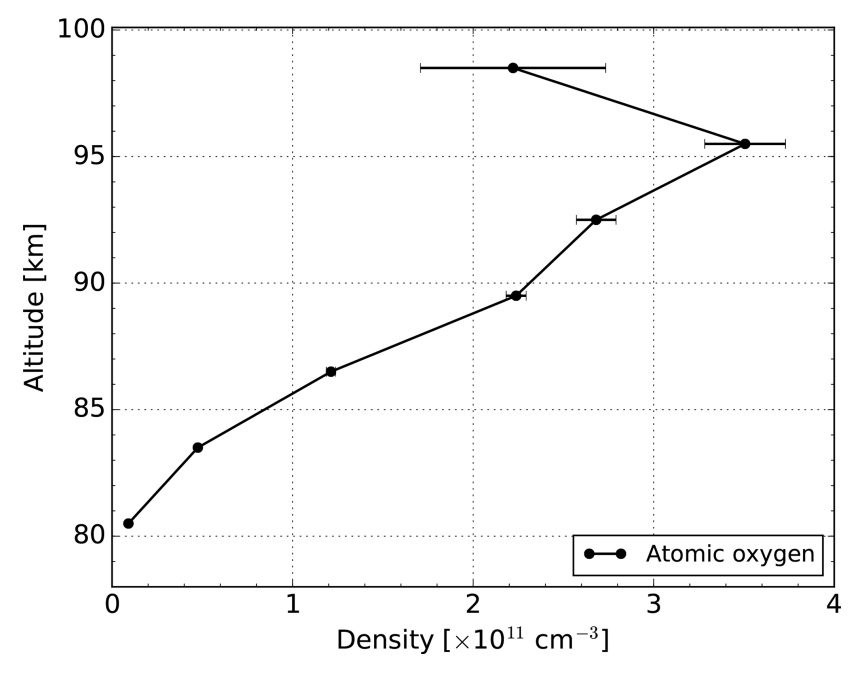

Figure 6. Atomic oxygen abundances, derived from GOMOS monthly zonal mean measurements of $\mathrm{OH}(8-4)$ airglow emissions for February 2006 at $10-20^{\circ} \mathrm{N}$. The error bar represents the statistical uncertainty coming from the measurement noise. It increases towards higher altitudes as a consequence of the corresponding SNR being lower.

atomic oxygen abundances. It includes a number of emission lines from $\mathrm{OH}(v=8-4)$ band, which originates from the radiative transitions of $\mathrm{OH}\left(v^{\prime}=8 \longrightarrow v^{\prime \prime}=4\right)$. The dominant emission lines are mainly in the $R$ branch with a rotational state quantum number of $K^{\prime \prime}=1,2$ and 3 .

The quality of the reprocessed spectra is evaluated by calculating the standard deviation (SD) of averaged spectra for each sample bin, supplemented by the SNR analysis. The calculations show that the mean SD for a typical sample bin in autumn at midlatitudes is around 2-
$4 \times 10^{9}$ photons $\mathrm{s}^{-1} \mathrm{~cm}^{-2} \mathrm{~nm}^{-1} \mathrm{sr}^{-1}$ and that SNR increases to more than 10 at peak altitudes and to around 3-5 at lower altitudes. A typical profile of processed hydroxyl spectra and integrated radiance is illustrated in Fig. 4. Three lines are clearly visible in the spectra (Fig. 4a), while the emission peak layer appears at the tangent altitude of around $85 \mathrm{~km}$, according to Fig. 4b. The error bars in Fig. 4b indicate the measurement noise for integrated radiance. The measurement noise is calculated from the standard deviation of the residual noise in the spectral range in between of the emission lines and assumed to be the same for all wavelengths, as the intensities of remaining weak emission lines from high rotational levels in the spectral region are by several orders of magnitude lower and therefore negligible. For the integrated radiance, the measurement noise is increased by a factor of $\sqrt{N}$, and $N$ refers to the number of integrated wavelength points.

\section{OH airglow modeling and retrieval methods}

The method to derive atomic oxygen abundance relies on the chemical equilibrium between ozone production and loss during nighttime. It is also applied for the retrieval of atomic oxygen abundances from SABER (Mlynczak et al., 2018) and SCIAMACHY (Zhu and Kaufmann, 2018) OH measurements. Ozone is produced in the three-body recombination reaction of atomic and molecular oxygen. Ozone is destroyed in reactions with atomic hydrogen and oxygen. As summarized in Table 1, most of the model parameters are adopted from Zhu and Kaufmann (2018). Additionally, the rate coefficients for the production of $\mathrm{OH}(v=8)$ by the collision of $\mathrm{OH}(v=9)$ with oxygen and the collisional removal of $\mathrm{OH}(v=8)$ by atomic oxygen are obtained by simultaneously 
fitting the limb radiances of $\mathrm{OH}(9-6)$ and $\mathrm{OH}(8-5)$ bands, which are independently taken from the SCIAMACHY measurements. These two parameters are adjusted in such a way that the ratio between the fitted radiances of the two bands is consistent with the ratio calculated from the measurements. Details about the fitting of the parameters are provided in Appendix A.

Atmospheric background profiles of temperature, total density and ozone mixing ratio are taken from SABER measurements (v2.0-2016). The same latitude bins $\left( \pm 5^{\circ}\right)$ and local times $( \pm 1 \mathrm{~h})$ were selected for SABER data as those for GOMOS data. Since SABER cannot measure $\mathrm{O}_{2}$ and $\mathrm{N}_{2}$ mixing ratios, these quantities are taken from the mass spectrometer incoherent scatter (MSIS) simulation model data (Picone et al., 2002).

The inverse model applies a constrained global-fit approach following the formalism of Rodgers (2000). The Gauss-Newton iterative method in the $n$ form (Rodgers, 2000 , p. 85) is chosen to minimize the cost function of this inverse problem. Besides, a priori information about the atmospheric state is included in the retrieval for regularization to mitigate the influence of measurement errors. The a priori information about atomic oxygen in this work is taken from MSIS model data, and the zeroth- and first-order Tikhonov regularization matrices (Tikhonov and Arsenin, 1977) are considered in the cost function. The a priori data about the absolute value of atomic oxygen are taken from the MSIS model, which is averaged into the vertical grid of $3 \mathrm{~km}$ as the measurements. The first-order regularization is obtained from the linear interpolation of the a priori data given on the measurement grid; i.e., no sub-measurement-grid information is obtained from that data. The regularization strength depends on altitude and its main purpose is to assure meaningful values at the upper and lower boundaries of the altitude regime considered. In between, the regularization has virtually no effect on the retrieved quantities, as can be seen from the retrieval diagnostics. The vertical resolution of the retrieval results is close to the vertical grid of the measurements. The target parameters of the retrieval are the vertical profiles of atomic oxygen abundance, spectral resolution and a wavelength shift. The latter are both altitude-independent and give a better agreement between measured and simulated spectra. The content of information in the spectra is sufficient to retrieve these additional parameters.

\section{Results}

\subsection{Atomic oxygen abundances}

Applying the global fitting method to GOMOS level-1b limb products, a globally distributed time series [O] dataset is derived, along with other quantities. Shown in Fig. 5a is a typical profile of the fitted spectra compared with the measurements. In general, simulations and measurements are in good agreement. The spectrally integrated radiances in Fig. 5b also show consistency. The derived oxygen densities are within an altitude range of 80 to $100 \mathrm{~km}$, covering the period from May 2002 to December 2011 and spanning local times from 22:00 to 00:00 LT. A typical atomic oxygen profile is shown in Fig. 6 with a maximum concentration of about $3.5 \times 10^{11}$ atoms $\mathrm{cm}^{-3}$ at $95 \mathrm{~km}$. Above the maximum, there is a downward flux of atomic oxygen by diffusive transport (Swenson et al., 2018). Turbulence associated with gravity wave breaking, along with damped waves or tides, is the dynamic process that contributes to this diffusive transport (Smith et al., 1987; Li et al., 2005). Below the maximum, there is a rapid decrease in atomic oxygen density, which is mainly due to the vertical transport and chemical losses. At an altitude of around $85 \mathrm{~km}$, atomic oxygen density already declines by 1 order of magnitude to $10^{10}$ atoms $\mathrm{cm}^{-3}$. The typical value of simultaneously retrieved spectral resolution is around $0.48 \mathrm{~nm}$, and no wavelength shift is found.

\subsection{Error analysis}

The total uncertainty of the derived atomic oxygen densities not only depends on the measurement noise but also on the smoothing error as well as on uncertainties in forward model parameters and the background atmosphere input. The largest source of uncertainties is found in the forward model parameters. The influence of these uncertainties on the results is assessed through error propagation, by the perturbation of forward model parameters. The chemical reaction rate coefficient $k_{1}$ has an uncertainty of around $20 \%$, contributing around $15 \%$ uncertainty below $90 \mathrm{~km}$ and around $20 \%$ at $95 \mathrm{~km}$ in derived abundances. $k_{3}$ introduces an increasing uncertainty of up to $6 \%$ at $95 \mathrm{~km}$. The nascent branching factor (e.g., $\left.f_{8}, f_{9}\right)$ explains the distribution ratio of excited hydroxyl radicals $\mathrm{OH}^{*}$ of different vibrational levels. $f_{8}$ has a linear influence on the uncertainty of the results; a perturbation of $10 \%$ on its values results in a similar retrieval uncertainty. The errors of Einstein coefficients correspond to an uncertainty of around $7 \%$ in the results. The uncertainty in the quenching coefficient $k_{\mathrm{N}_{2}(8)}$ of $\mathrm{OH}^{*}$ radicals with nitrogen molecules introduces a uncertainty of $14 \%$ at $80 \mathrm{~km}$, which decreases to $5 \%$ at $95 \mathrm{~km}$, and the uncertainty in the rate coefficient for quenching by molecular oxygen $k_{\mathrm{O}_{2}(8)}$ corresponds to an uncertainty of $5 \%$ at $85 \mathrm{~km}$ and $2 \%$ at $95 \mathrm{~km}$. The influences of other model parameters are on the order of $1 \%-2 \%$ or less. SABER temperature uncertainties are the predominant factor influencing the retrieval results in the background atmosphere. The uncertainties are around $5.5 \mathrm{~K}$ at $80 \mathrm{~km}$ and increase to $13 \mathrm{~K}$ at $90 \mathrm{~km}$ (Dawkins et al., 2018). Through error propagation calculation, this could lead to an uncertainty of $5 \%$ below $90 \mathrm{~km}$ and up to $20 \%$ above $95 \mathrm{~km}$, taking into account the compensation effects of total density changes following the hydrostatic equilibrium (Zhu and Kaufmann, 2018). 
Table 1. $\mathrm{OH}$ airglow modeling parameters used in this study, where $k_{1}$ to $k_{3}$ represent the chemical reaction rate coefficient; $f_{9}$ and $f_{8}$ refer to the $\mathrm{OH}^{*}$ nascent production branching ratio for vibrational level $v=9$ or 8 ; and $k_{\mathrm{N}_{2}}, k_{\mathrm{O}_{2}}$ and $k_{\mathrm{O}}$ represent the quenching coefficients of $\mathrm{OH}^{*}$ radicals by $\mathrm{N}_{2}, \mathrm{O}_{2}$ and $\mathrm{O}$.

\begin{tabular}{|c|c|c|c|}
\hline Parameter & Process & Rate constant & Reference \\
\hline$k_{1}$ & $\mathrm{O}+\mathrm{O}_{2}+M$ & $6.0 \times 10^{-34}(300 / T)^{2.4} \mathrm{~cm}^{6} \mathrm{~s}^{-1}$ & Sander et al. (2011) \\
\hline$k_{2}$ & $\mathrm{H}+\mathrm{O}_{3}$ & $1.4 \times 10^{-10} \exp (-470 / T) \mathrm{cm}^{3} \mathrm{~s}^{-1}$ & Sander et al. (2011) \\
\hline & $\mathrm{O}+\mathrm{O}_{3}$ & $8.0 \times 10^{-12} \exp (-2060 / T) \mathrm{cm}^{3} \mathrm{~s}^{-1}$ & Sander et al. (2011) \\
\hline$f_{9} \& f_{8}$ & $\mathrm{OH}^{*}$ nascent branching factor & $0.47 \& 0.34$ & Adler-Golden (1997) \\
\hline$k_{\mathrm{N}_{2}(8)}$ & $\mathrm{OH}(8)+\mathrm{N}_{2}$ & $1.4 \times(7 \pm 4) \times 10^{-13} \mathrm{~cm}^{3} \mathrm{~s}^{-1 *}$ & $\begin{array}{l}\text { Adler-Golden (1997) } \\
\text { (Table 1, measured by Dyer et al., 1997) }\end{array}$ \\
\hline$k_{\mathrm{O}_{2}(8)}$ & $\mathrm{OH}(8)+\mathrm{O}_{2}$ & $1.18 \times(8 \pm 1) \times 10^{-12} \mathrm{~cm}^{3} \mathrm{~s}^{-1^{*}}$ & $\begin{array}{l}\text { Adler-Golden (1997) } \\
\text { (Table 1, measured by Dyer et al., 1997) }\end{array}$ \\
\hline$k_{\mathrm{O}(8)}$ & $\mathrm{OH}(8)+\mathrm{O}$ & $6.5 \times 10^{-11} \mathrm{~cm}^{3} \mathrm{~s}^{-1}$ & This work \\
\hline$k_{\mathrm{O}_{2}(9,8)}$ & $\mathrm{OH}(9)+\mathrm{O}_{2} \rightarrow \mathrm{OH}(8)+\mathrm{O}_{2}$ & $1.18 \times 8.9 \times 10^{-13} \mathrm{~cm}^{3} \mathrm{~s}^{-1 *}$ & This work \\
\hline$k_{\mathrm{N}_{2}(9)}$ & $\mathrm{OH}(9)+\mathrm{N}_{2}$ & $1.4 \times(7 \pm 2) \times 10^{-13} \mathrm{~cm}^{3} \mathrm{~s}^{-1^{*}}$ & Kalogerakis et al. (2011) \\
\hline$k_{\mathrm{O}_{2}(9)}$ & $\mathrm{OH}(9)+\mathrm{O}_{2}$ & $1.18 \times(2.2 \pm 0.6) \times 10^{-11} \mathrm{~cm}^{3} \mathrm{~s}^{-1 *}$ & Kalogerakis et al. (2011) \\
\hline$k_{\mathrm{O}(9)}$ & $\mathrm{OH}(9)+\mathrm{O}$ & $(2.3 \pm 1) \times 10^{-10} \mathrm{~cm}^{3} \mathrm{~s}^{-1}$ & Kalogerakis et al. (2016) \\
\hline
\end{tabular}

* A low-temperature scale factor, as the mesopause temperature is normally much lower than the laboratory conditions (Lacoursiére et al., 2003; Panka et al., 2017).
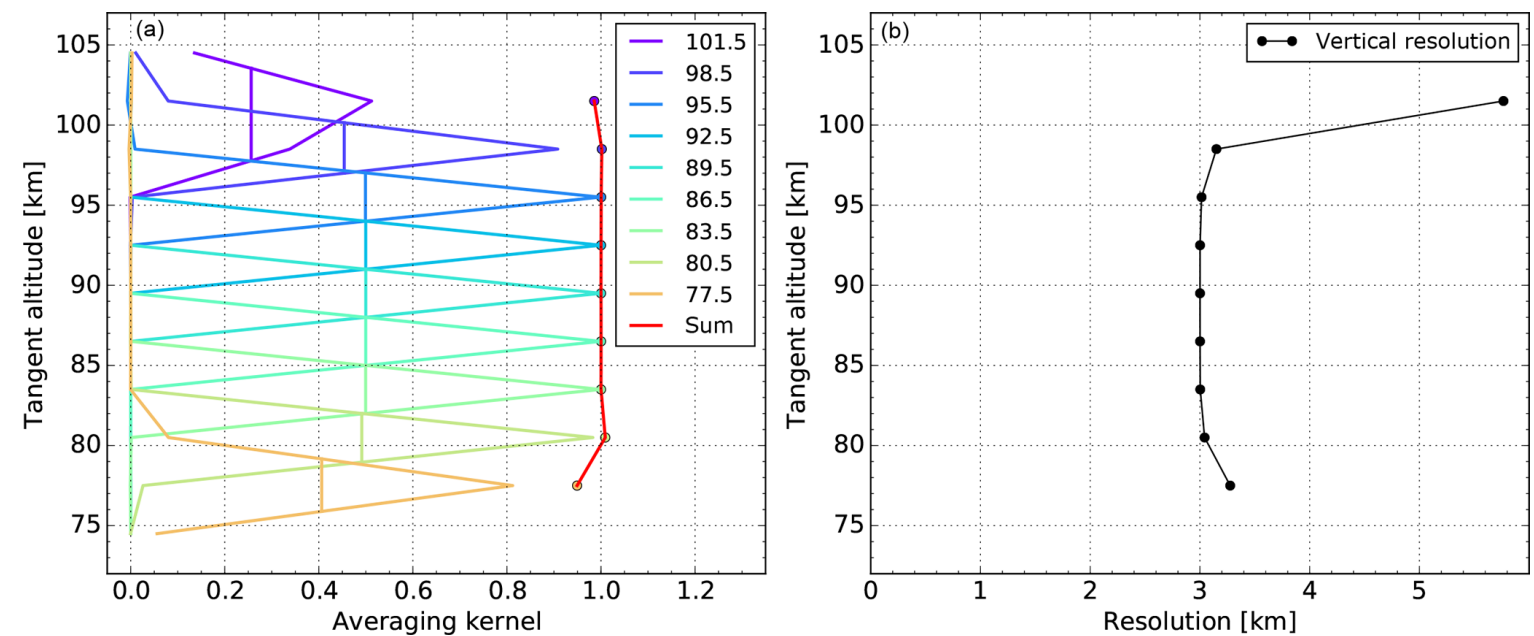

Figure 7. (a) The averaging kernel and (b) the vertical resolution of the retrieval for February 2006 at $10-20^{\circ} \mathrm{N}$ and a local time of $22: 00-$ 00:00 LT. The vertical resolution is obtained from the distribution of each row in the averaging kernel by calculating the corresponding FWHM.

At the altitude of $80-100 \mathrm{~km}$, the effects of the smoothing error and measurement noise on the uncertainty are on the order of $0.5 \%$ and $5 \%$, respectively. It is due to a properly chosen regularization in the retrieval procedure that the a priori information is negligible in the retrieval results. As part of a more in-depth look into the retrieval results, the averaging kernel and vertical resolution are investigated, as shown in Fig. 7. The summed-up averaging kernels for each row in the altitude region of interest $(80-100 \mathrm{~km})$ are equal to 1 , indicating that the measurements instead of the a priori information contribute to nearly all of the retrieval result. The peaks of averaging kernels are found at the tangent altitudes and the corresponding vertical resolution for each altitude is around $3 \mathrm{~km}$, which is close to the vertical spacing of the limb measurements. Since the sum of the averaging kernels is also near 1 , the a priori influence is generally low.

\subsection{Spatial and temporal analysis}

Atomic oxygen reveals a two-cell structure near $95 \mathrm{~km}$ at midlatitudes, which is most pronounced during the equinox seasons (Fig. 8). The smallest values appear over the equatorial region and the largest values are at midlatitudes. As already mentioned and discussed by Smith et al. (2010) and $\mathrm{Xu}$ 


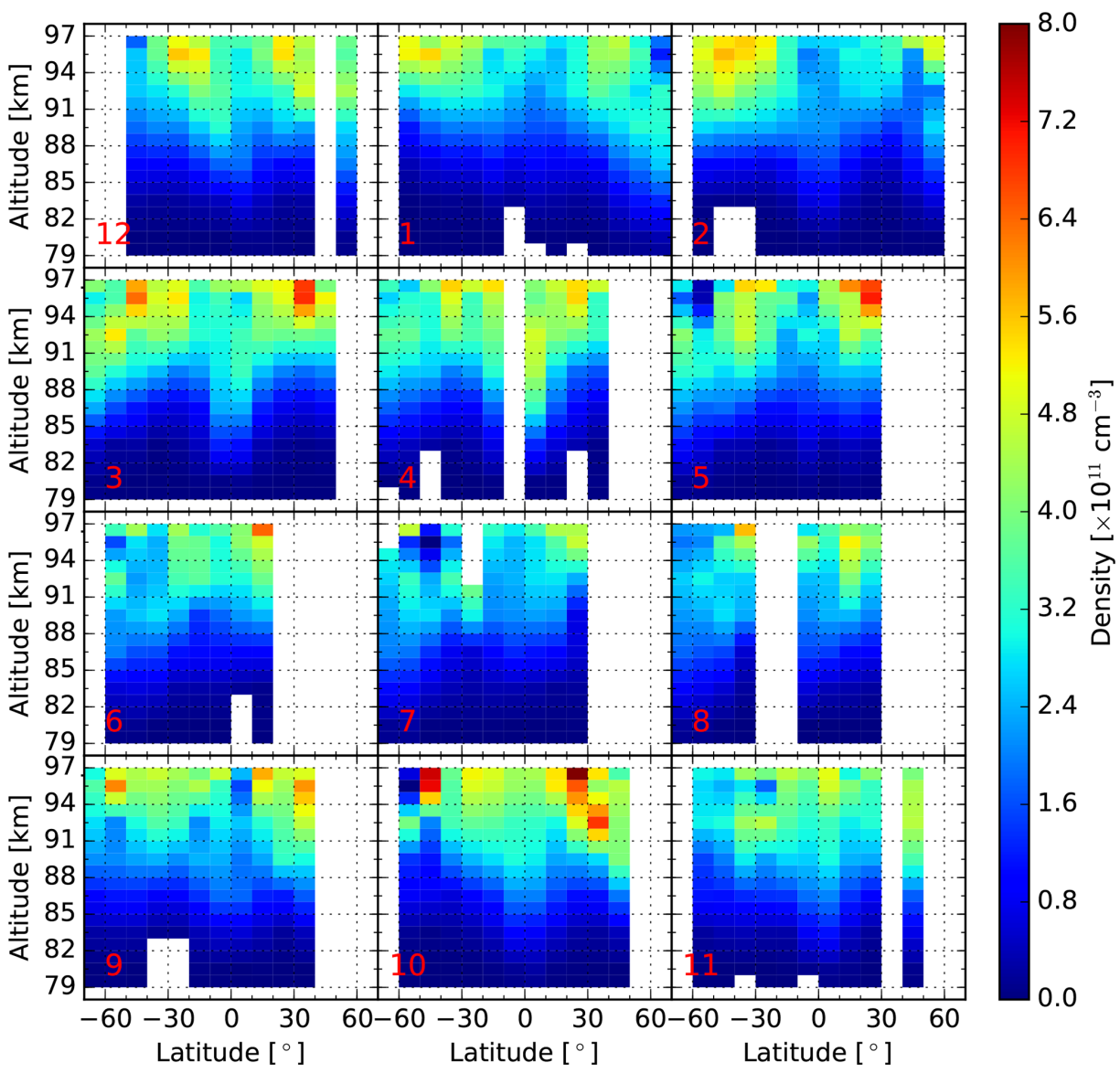

Figure 8. Latitude-altitude distribution of the zonal mean atomic oxygen density for 2007. Each row represents approximately a season. The data are linearly interpolated into a $1 \mathrm{~km}$ altitude grid for better illustration. The numbers in the subplots indicate the month of the year.

et al. (2010), the latitudinal distribution structure of atomic oxygen is influenced by tides. The vertical transport of air caused by tides leads to a vertical displacement of atomic oxygen. At a local time of almost midnight (the mean local time of the GOMOS measurements is around 23:00 LT, 22:00 to 00:00 LT), the atomic oxygen displacement by tides at the mesopause is upward at the Equator (resulting in an [O] decrease) and downward in subtropical latitudes (resulting in an $[\mathrm{O}]$ enrichment).

In Fig. 9, a vertical distribution comparison of derived densities from 2002 to 2011 over the midlatitude and equatorial regions is shown. Both the annual oscillation $(\mathrm{AO})$ and semiannual oscillation (SAO) can be seen from the temporal evolution of middle and lower latitudes. The SAO reaches its maximum at equinox seasons, which is related to the semiannual variation of the atmospheric tide amplitudes (Smith et al., 2010).

A multiple linear regression analysis is applied to quantitatively analyze the longtime variations of the GOMOS [O] dataset. The monthly mean column density integrated from 80 to $97 \mathrm{~km}$ for $20-30^{\circ} \mathrm{N}$ is analyzed by harmonic fitting, which includes components such as the solar cycle effect,
$\mathrm{SAO}, \mathrm{AO}$ and $\mathrm{QBO}$ (quasi-biennial oscillation), and baseline.

$$
\begin{aligned}
{[O]_{\text {Column }} } & =\text { baseline }+A_{\text {solar }} \cdot I_{\text {solar }}(t+\text { shift }) \\
& +A_{\mathrm{SAO}} \cdot \cos \left(\frac{2 \pi t}{6}+P_{\mathrm{SAO}}\right) \\
& +A_{\mathrm{AO}} \cdot \cos \left(\frac{2 \pi t}{12}+P_{\mathrm{AO}}\right) \\
& +A_{\mathrm{QBO}} \cdot \cos \left(\frac{2 \pi t}{27.5}+P_{\mathrm{QBO}}\right)
\end{aligned}
$$

The variable $t$ represents the month since 2002 and the column density is fitted by amplitudes $\left(A\right.$, atoms $\left.\mathrm{cm}^{-3}\right)$ and phase shifts $(P$, months) of SAO (period of 6 months), AO (period of 12 months) and QBO (period of 27.5 months), complemented by the amplitude $\left(A_{\text {solar }}\right.$, atoms $\left.\mathrm{cm}^{-3} \mathrm{sfu}^{-1}\right)$ and shift of the 11-year solar cycle effect, as well as a baseline. The coefficient $I_{\text {solar }}$ is the solar radio flux proxy $\left(F_{10.7} \mathrm{~cm}\right.$, in units of sfu) taken from Tapping (2013). The typical mesospheric QBO (MQBO) period is about 27.5 months by investigating mesospheric zonal wind measurements (Ratnam et al., 2008; de Wit et al., 2013; Malhotra et al., 2016). The baseline is given as the averaged value 


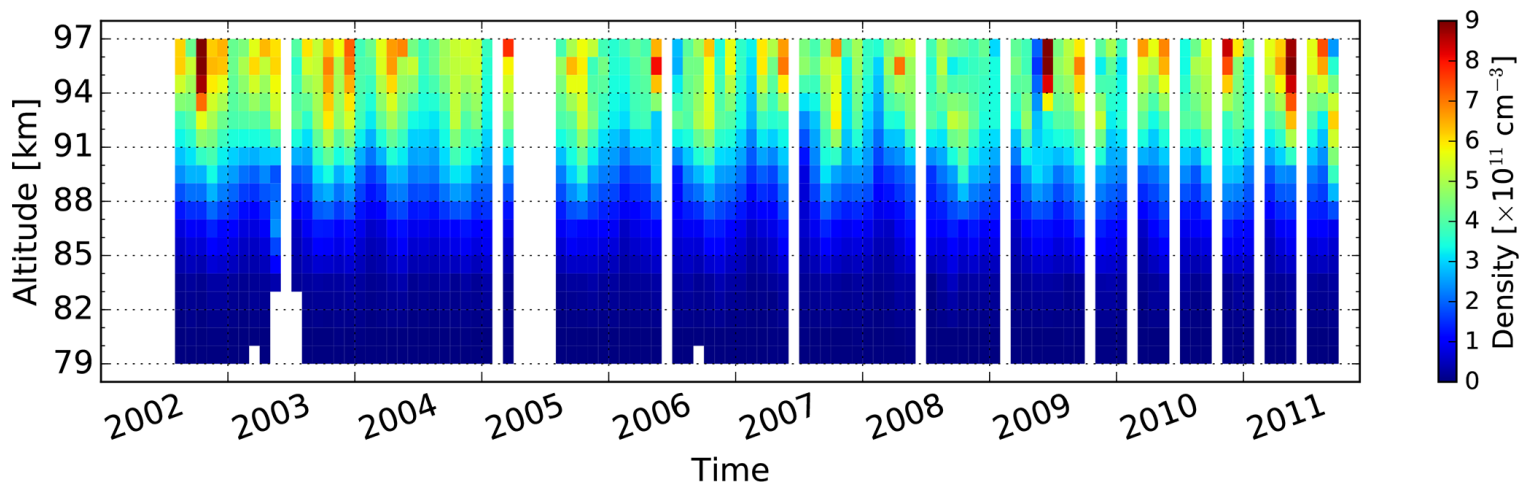

(a) $20^{\circ}-40^{\circ} \mathrm{N}$

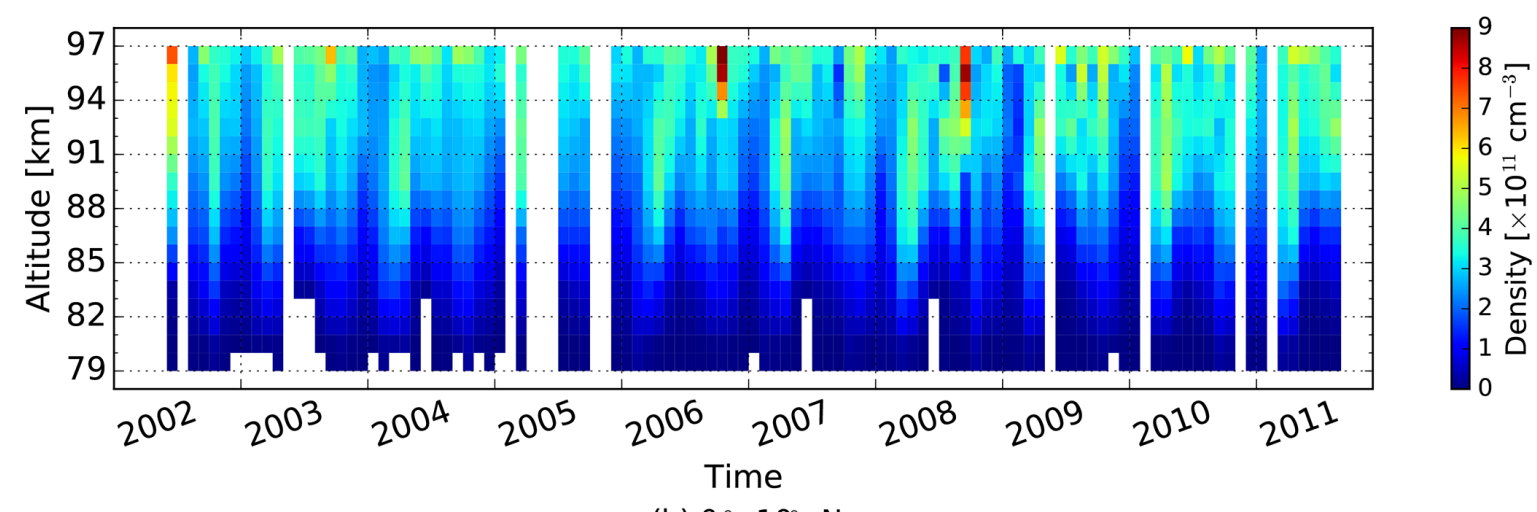

(b) $0^{\circ}-10^{\circ} \mathrm{N}$

Figure 9. Temporal evolution of the vertical distribution of monthly zonal mean atomic oxygen densities for $20-40^{\circ} \mathrm{N}\left(\right.$ a) and $0-10^{\circ} \mathrm{N}$ (b). The data are linearly interpolated into a $1 \mathrm{~km}$ altitude grid.

of the monthly mean column densities along the time series. The non-linear least squares fitting method (LevenbergMarquardt algorithm) is applied to derive these fitting parameters, as described in detail by Kaufmann et al. (2013) and Zhu et al. (2015).

In Fig. 10, the raw data and the fitting results are illustrated in panel (a). Besides, the baseline plus the solar terms are also shown in the plot. The solar min and solar max values denote the fitted atomic oxygen column densities solely from the solar cycle component, under the solar minimum and solar maximum conditions, respectively. The $\mathrm{SAO}$ and $\mathrm{AO}$ components from the harmonic fitting are given in Fig. 10b, c, respectively. The $[\mathrm{O}]$ longtime variations are well characterized by the fit. The 11-year solar cycle effect is captured, in which the atomic oxygen density is $17 \%$ smaller in 2008/2009 (minimum of solar cycles 23/24) than in 2002 (near solar maximum conditions of solar cycle 23), due to different radiative forcing conditions during the solar cycles. This agrees with model investigations and experimental results, which are normally in a range of around $10 \%$ to $30 \%$ (Schmidt et al., 2006; Marsh et al., 2007; Kaufmann et al., 2014; Zhu et al., 2015). A significant semiannual oscillation is observed, reaching a maximum in equinox seasons, which is in agreement with the analysis above for Fig. 9, and the amplitude is about $18 \%$ (with respect to the baseline). The annual oscillation has an amplitude of $10 \%$, with the maximum being reached near summer solstices and the minimum near winter solstices. These results are consistent with the analyses of Zhu et al. (2015) and Lednyts'kyy et al. (2017), which reported SAO amplitudes on the order of $15 \%$ and $12 \%, \mathrm{AO}$ amplitude of $11 \%$ and $7 \%$, respectively. The QBO amplitude is on the order of $2 \%$. The multiple linear fitting analyses on other latitudinal bands and altitudes also show a similar solar cycle effect as well as AO and SAO variations, as some examples are summarized in Table 2.

It could be considered to add an additional slope term in the harmonic fitting (Eq. 1) as well. In that case, the agreement between measurements and the fit increases marginally by about $2 \%$ with an additional slope term. But the fitting parameters are not independent any longer, because a strong correlation between the slope, the baseline and the solar terms is found, which was not the case before. This indicates that the inversion problem (to obtain the fitting parameters) is now underdetermined. As an alternative approach, the solar $\left(F_{10.7}\right)$ fitting parameter could be replaced by the slope term. In this case, the residual increases by about $5 \%$ and the fitting parameters are not correlated (except for the offset and slope terms). From a mathematical point of view, this is an alter- 


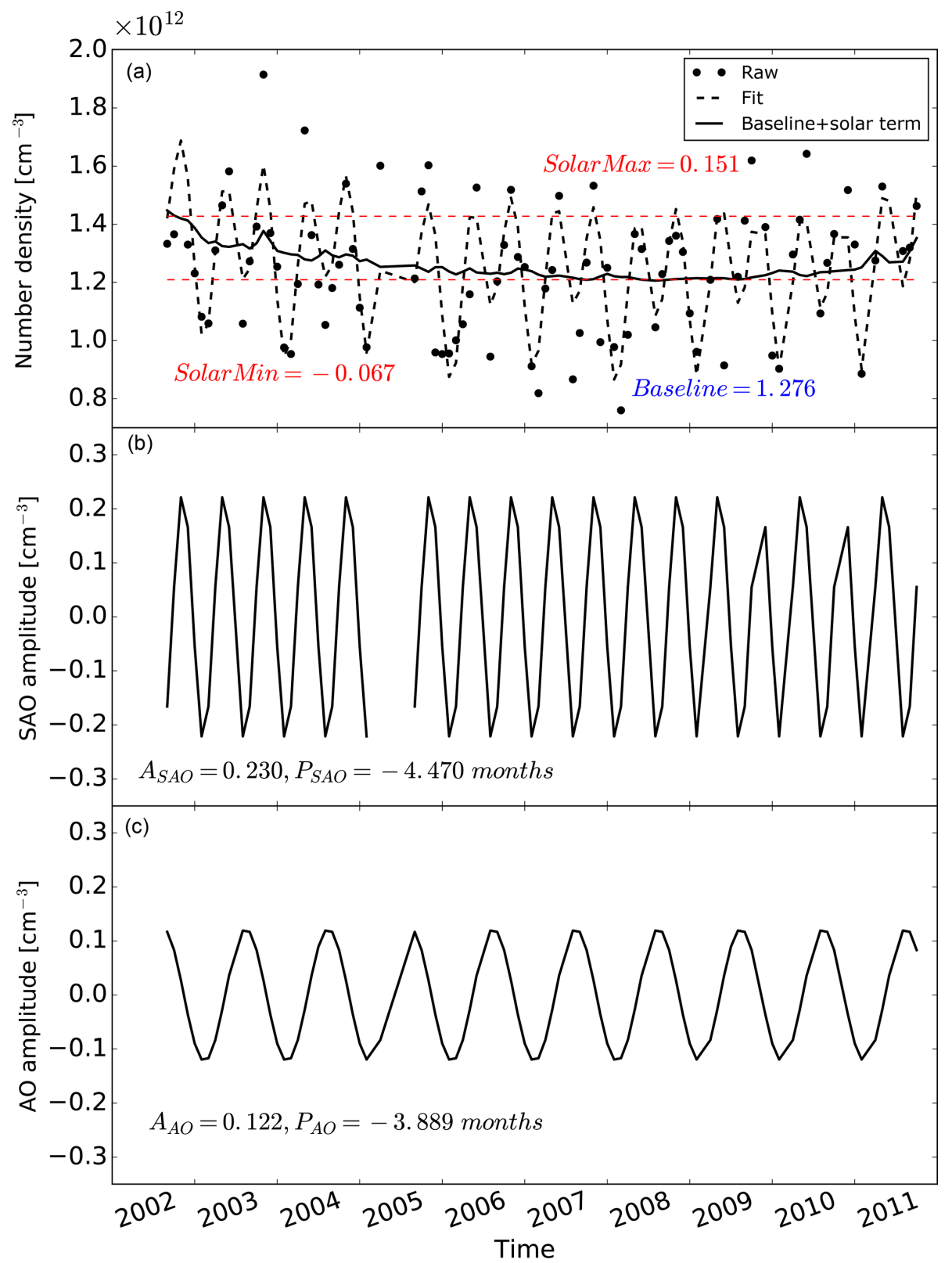

Figure 10. Multiple linear regression analysis of vertically integrated, monthly mean atomic oxygen densities of $80-97 \mathrm{~km}$ for $20-30^{\circ} \mathrm{N}$ from 2002 to 2011. (a) The raw and fitted data are shown along with the baseline plus the solar components in the multiple linear regression results. The solar min and solar max values denote the fitted atomic oxygen column densities solely from the solar cycle component, under the solar minimum and solar maximum conditions, respectively. (b) SAO and (c) AO parts are also illustrated with corresponding parameters. $A_{\mathrm{SAO}}, P_{\mathrm{SAO}}, A_{\mathrm{AO}}$ and $P_{\mathrm{AO}}$ are the amplitudes and phase shifts of $\mathrm{SAO}$ and $\mathrm{AO}$, respectively. The quantities of solar min, solar max, baseline and amplitudes are in units of $10^{12}$ atoms $\mathrm{cm}^{-3}$. The phase shifts are in units of months. The gap present in the SAO is caused by the data discontinuity.

native to the original fit (with solar but without slope terms). For this setup, the slope is $-0.0002 \times 10^{12} \mathrm{~cm}^{-3}$ month $^{-1}$, which means that there is virtually no trend apparent in the data. This can be explained if the change over time is considered as a combination of two linear trends, with a negative slope in the declining phase of the solar cycle and a positive slope in the following inclining phase. This hypothesis can be underpinned by looking at a subset of the time series, covering the time period from 2002 to 2009, only (roughly solar maximum to solar minimum). The slope for this period is about $-3 \%$ per year, indicating a linear decrease of atomic oxygen by $21 \%$ for the given period. If the $F_{10.7}$ dependency is considered instead, a similar drop is modeled if a solar term with an amplitude of $0.0025 \times 10^{12} \mathrm{~cm}^{-3} \mathrm{sfu}^{-1}$ is 
Table 2. Summary of multiple linear regression analysis results of monthly mean atomic oxygen column densities integrated over 80-97 km for $20-30^{\circ} \mathrm{N}, 0-10^{\circ} \mathrm{N}$ and $20-30^{\circ} \mathrm{S}$ from 2002 to 2011 . The quantities are in units of $10^{12}$ atoms cm $^{-3}$. The solar min and solar max values denote the fitted atomic oxygen column densities solely from the solar cycle component, under the solar minimum and solar maximum conditions, respectively. $A_{\mathrm{SAO}}, A_{\mathrm{AO}}$ and $A_{\mathrm{QBO}}$ are the amplitudes of $\mathrm{SAO}, \mathrm{AO}$ and $\mathrm{QBO}$, respectively.

\begin{tabular}{lrrrrrr}
\hline Latitude bin & Baseline & Solar max & Solar min & $A_{\mathrm{SAO}}$ & $A_{\mathrm{AO}}$ & $A_{\mathrm{QBO}}$ \\
\hline $20-30^{\circ} \mathrm{N}$ & 1.276 & 0.151 & -0.067 & 0.23 & 0.122 & 0.022 \\
$0-10^{\circ} \mathrm{N}$ & 1.221 & 0.085 & -0.044 & 0.272 & 0.126 & 0.05 \\
$20-30^{\circ} \mathrm{S}$ & 1.126 & 0.097 & -0.052 & 0.183 & 0.074 & 0.025 \\
\hline
\end{tabular}

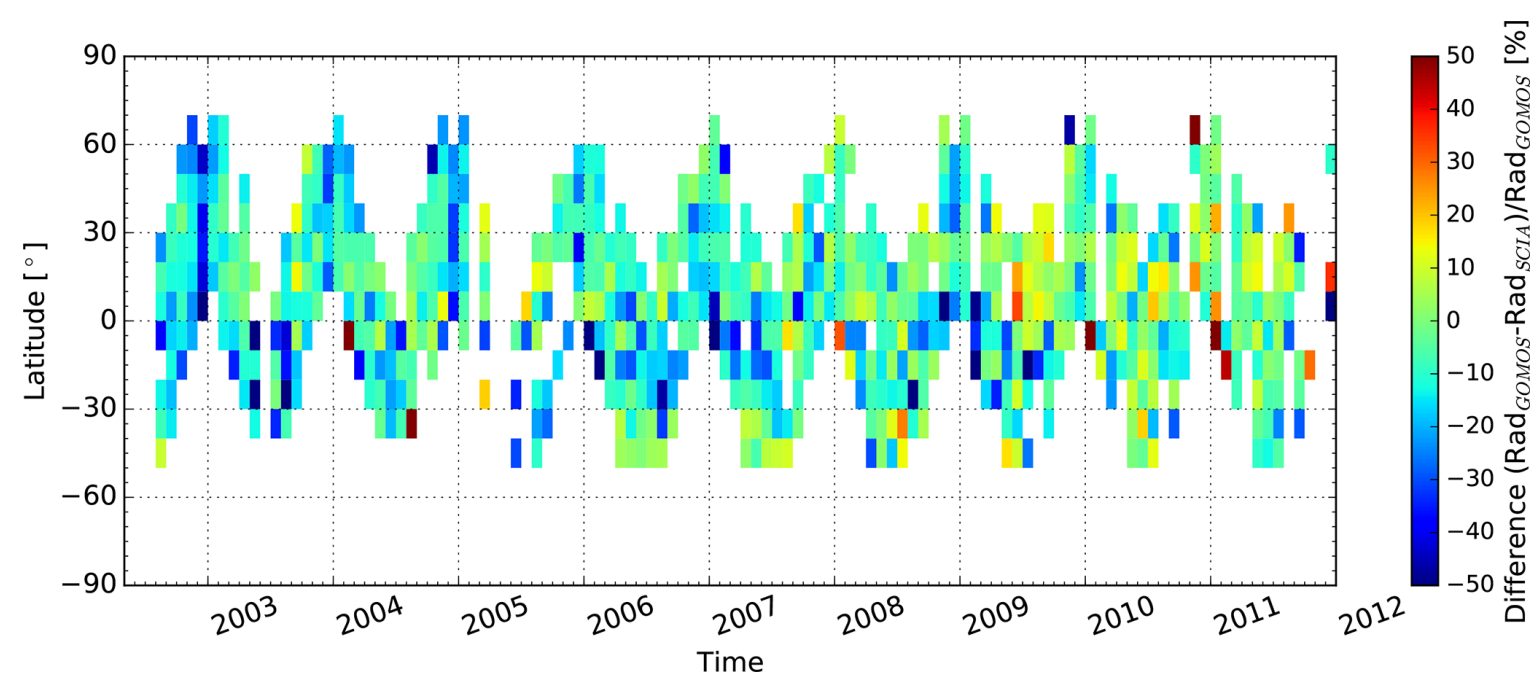

Figure 11. Temporal evolution of radiance differences (in percentage) between GOMOS and SCIAMACHY at a tangent altitude of 86.5 km. The radiance is integrated over the wavelength of $930-935 \mathrm{~nm}$. Negative numbers indicate that SCIAMACHY radiances are larger than those of GOMOS.

used. This value is similar to $0.002 \times 10^{12} \mathrm{~cm}^{-3} \mathrm{sfu}^{-1}$, which is the value obtained when the total time series is considered. This line of arguments indicates that there is more likely a solar $F_{10.7}$ dependency apparent in the data than a plain linear dependency.

\section{Discussion}

\subsection{Comparison with SCIAMACHY data}

The SCIAMACHY instrument, another limb sounder aboard the Envisat satellite, observed $\mathrm{OH}$ emissions at various wavelengths from visible to infrared emissions (Bovensmann et al., 1999; Kaufmann et al., 2008). This provides us with the best opportunity for a comprehensive joint investigation of the GOMOS [O] dataset, as SCIAMACHY covers exactly the same $\mathrm{OH}(8-4)$ band wavelengths as GOMOS. Two more datasets of [O] derived from SCIAMACHY green-line emissions (Kaufmann et al., 2014; Zhu et al., 2015) and OH(9-6) band airglow (Zhu and Kaufmann, 2018) are currently available.
SCIAMACHY performed the $\mathrm{OH}$ airglow measurements in dark limb-viewing mode in the flight direction, with the recorded spectra always near a local solar time of 22:00 LT and a fixed altitude grid of $3.3 \mathrm{~km}$. The $\mathrm{OH}(8-4)$ band observation is located in channel 5 with a spectral resolution of $0.54 \mathrm{~nm}$. SCIAMACHY data version $8-2016$ is adopted in this work. A continuous observation was performed during the entire lifetime of Envisat. The number of recorded profiles in one sample bin was around 100-300 before 2005 and significantly increased to $400-600$ because of a change in instrument operations. SNRs of single profiles are normally on the order of 6 at peak altitudes and decrease to 1 at lower altitudes. After monthly zonal averaging, SNRs increase by 1 order of magnitude, and the mean noise level is around $0.6 \times 10^{9}$ photons $\mathrm{s}^{-1} \mathrm{~cm}^{-2} \mathrm{~nm}^{-1} \mathrm{sr}^{-1}$.

Theoretically, the SCIAMACHY and GOMOS measurements should be identical in the same wavelength range. In practice, however, due to effects of various factors, such as instrument characteristics, radiometric calibration and fields of view, they do not fully conform with each other in terms of absolute radiance or instrument line shapes. In this study, the two data products are found to be consistent in terms of absolute radiance within $\pm 20 \%$ in the peak emissions layer 

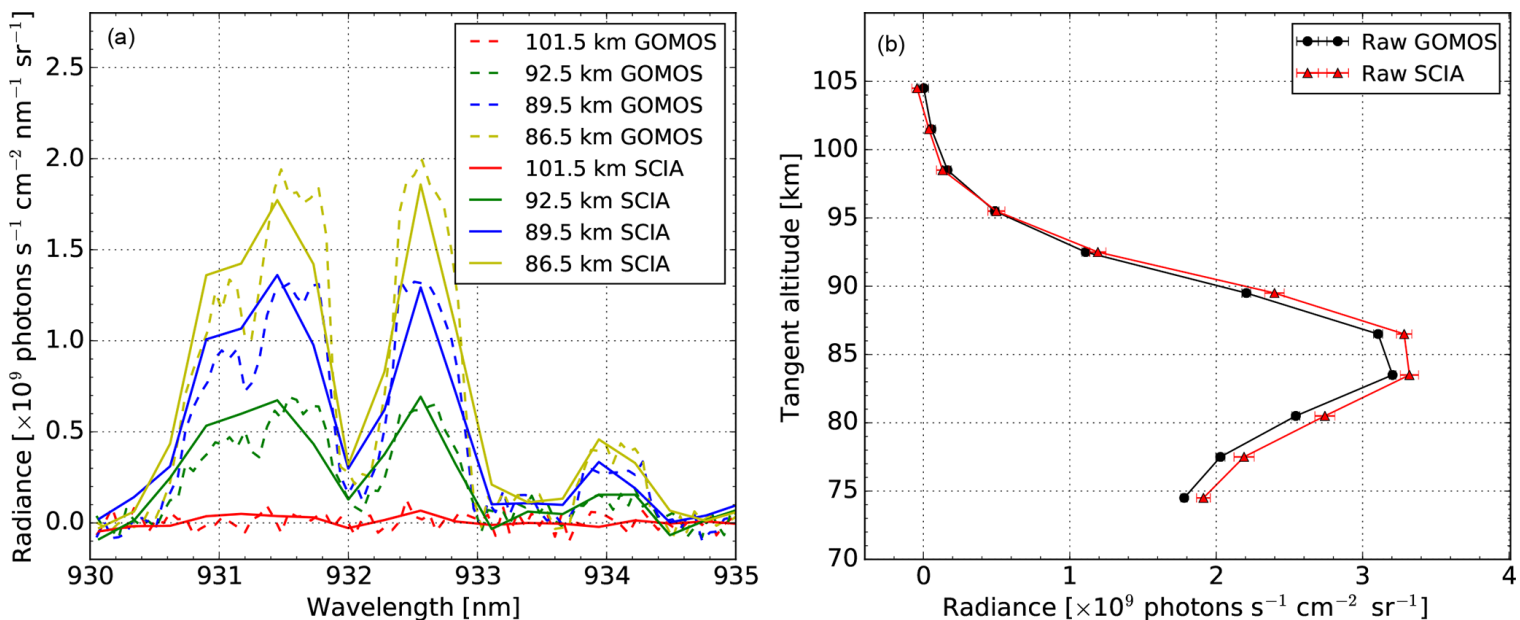

Figure 12. (a) SCIAMACHY (solid line) and GOMOS (dashed line) observations of monthly zonal mean OH(8-4) airglow emissions at the tangent altitudes, as given in the figure legend for April 2004 at $20-30^{\circ} \mathrm{N}$ and a local time of 22:00-00:00 LT. (b) The spectrally integrated radiance over 930-935 $\mathrm{nm}$ versus tangent altitude for the same conditions. The error bars are measurement noise, computed as in Fig. 4.

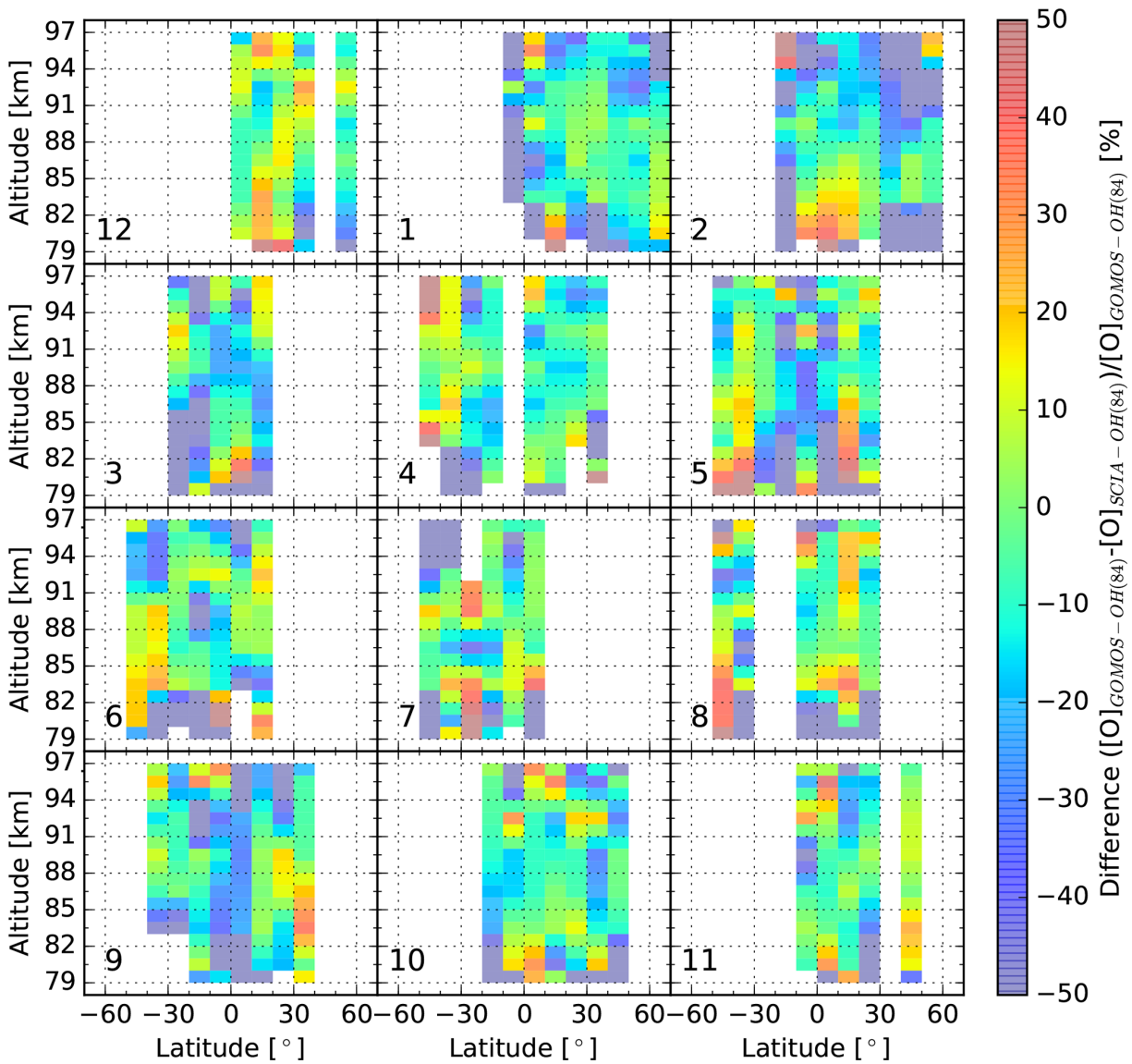

Figure 13. Latitude-altitude distribution of percentage differences between zonal mean atomic oxygen densities derived from GOMOS and SCIAMACHY OH(8-4) airglow emissions for 2007. Each row represents approximately a season. Negative numbers indicate that SCIAMACHY abundances are larger than those obtained from GOMOS. The data are linearly interpolated into a $1 \mathrm{~km}$ altitude grid. The numbers in the subplots indicate the month of the year. 


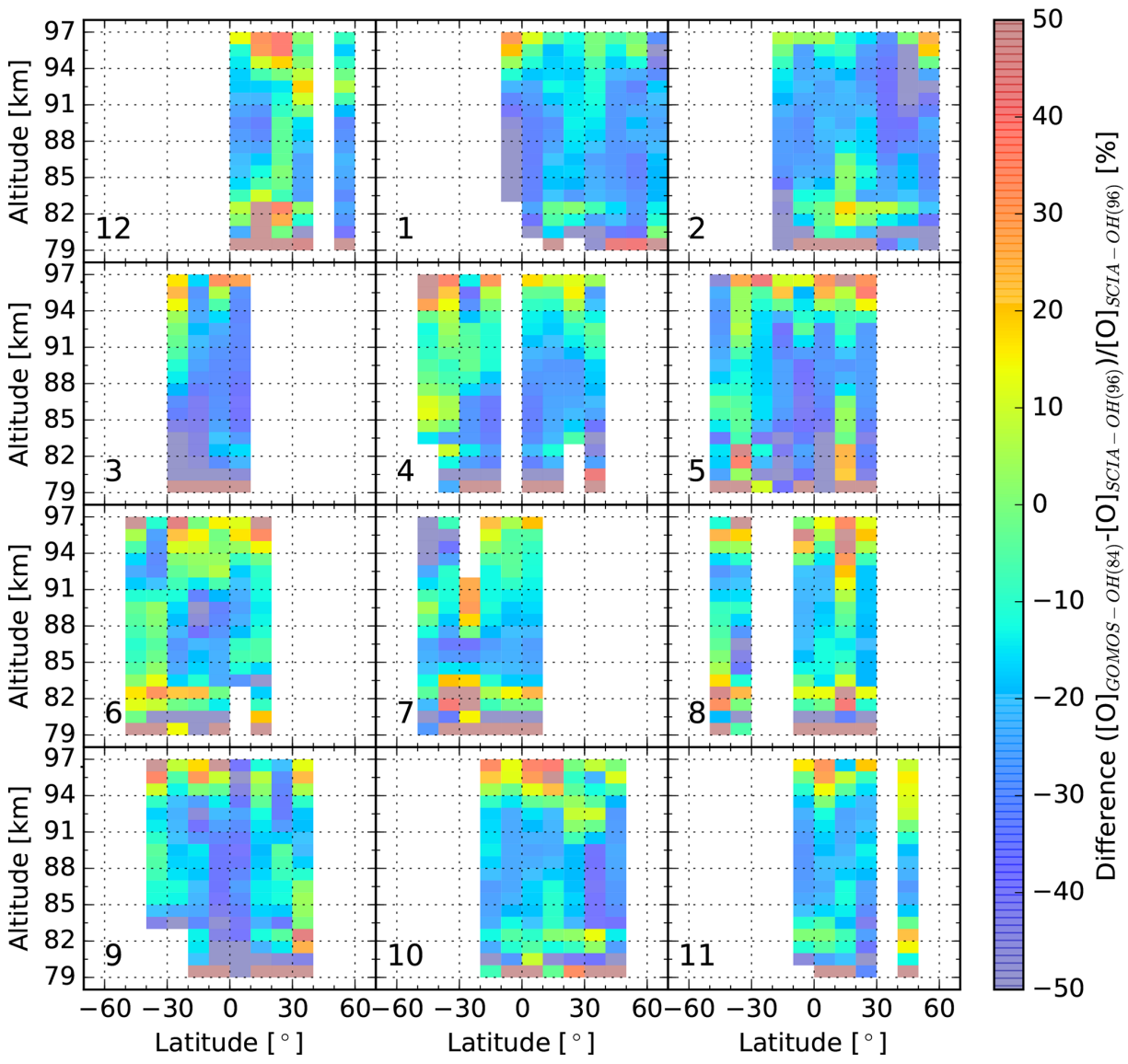

Figure 14. Latitude-altitude distribution of percentage differences between zonal mean atomic oxygen densities derived from GOMOS OH(8-4) and SCIAMACHY OH(9-6) airglow emissions for 2007. The SCIAMACHY OH(9-6) are taken from Zhu and Kaufmann (2018). This figure is plotted in a similar way to Fig. 13. Negative numbers indicate that SCIAMACHY OH(9-6) atomic oxygen abundances are larger than the GOMOS $\mathrm{OH}(8-4)$ abundances.

(shown in Fig. 11), after monthly zonal averaging. Particularly, the difference of the GOMOS data with the SCIAMACHY data is gradually becoming positive from negative over time, and the potential source for the drift could be a degradation of the GOMOS or SCIAMACHY instruments (Bramstedt et al., 2009), which is not fully corrected or overcompensated in the level- 0 calibration and the change of the system sensitivities over time. One specific example of spectra comparison is given in Fig. 12. The emission radiances from two data products are similar, but the GOMOS spectra are more noisy.

The same retrieval procedure is applied to the SCIAMACHY data. The differences between the atomic oxygen abundances from the two instruments are illustrated in Fig. 13. There are no major systematic discrepancies and they agree within a $\pm 20 \%$ difference in most latitudealtitude bins as expected from the differences of the corresponding radiances. The GOMOS data are found to be over $20 \%$ lower in the Northern Hemisphere in February and also in tropical regions in March, May and September. GOMOS values appear to be $20 \%$ larger at low altitudes of around
$80 \mathrm{~km}$ in some scattered bins. In general, these two atomic oxygen datasets derived from $\mathrm{OH}(8-4)$ airglow emissions agree with each other within the combined uncertainties in the context of absolute abundances.

Similarly, a latitude-altitude comparison of the GOMOS data with atomic oxygen obtained from SCIAMACHY $\mathrm{OH}(9-6)$ emissions (Zhu and Kaufmann, 2018) is given in Fig. 14 for 2007. In general, these two datasets agree with each other, but the GOMOS $\mathrm{OH}(8-4)$ dataset is found to be around $10 \%-20 \%$ lower than the SCIAMACHY OH(9-6) dataset in most latitude bins, especially in the altitude region of $85-95 \mathrm{~km}$. The difference between the two datasets becomes more than $20 \%$ at some data points near the Equator in March, May and September. Combing the derived results from SCIAMACHY OH(8-4), an intercomparison of the three datasets is given in Fig. 15 for different latitudinal and seasonal conditions. The absolute abundances of the three datasets are in the same order of magnitude and they agree with each other at the altitude region of interest of $80-95 \mathrm{~km}$. Specifically, atomic oxygen abundances derived from $\mathrm{OH}(8-4)$ emissions by both instruments are found to 


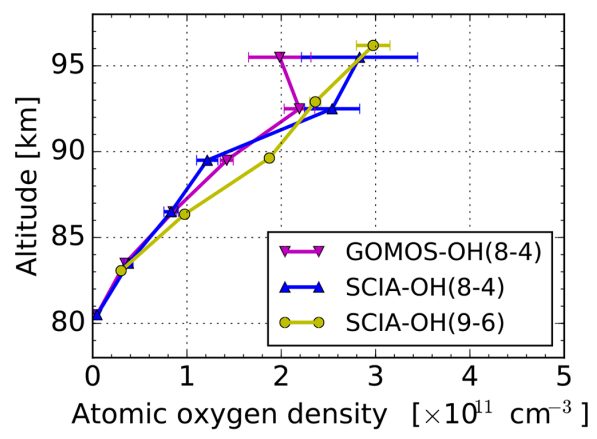

(a) $0^{\circ}-10^{\circ} \mathrm{N}$, Jan 2009

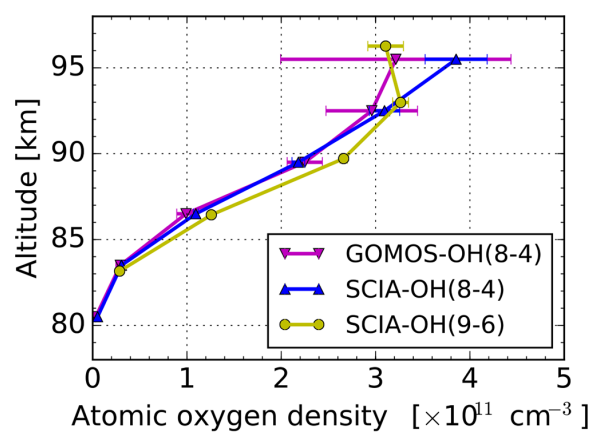

(c) $20^{\circ}-30^{\circ} \mathrm{S}$, Jun 2010

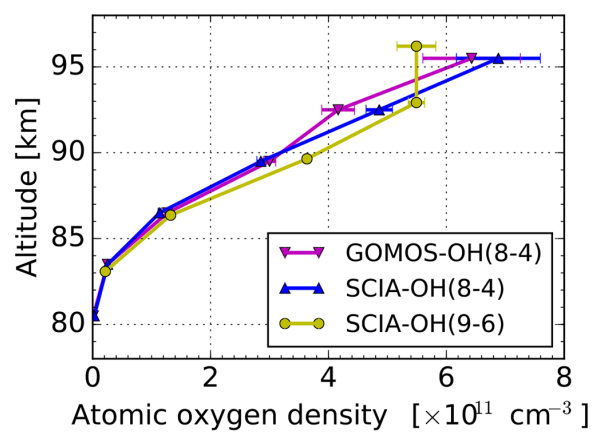

(e) $20^{\circ}-30^{\circ} \mathrm{N}$, Sep 2005

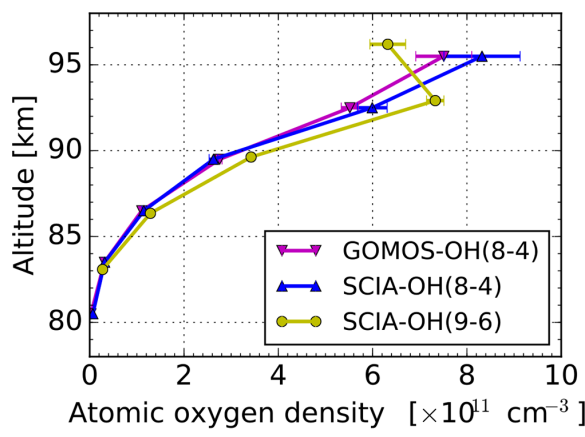

(b) $20^{\circ}-30^{\circ} \mathrm{N}$, Apr 2004

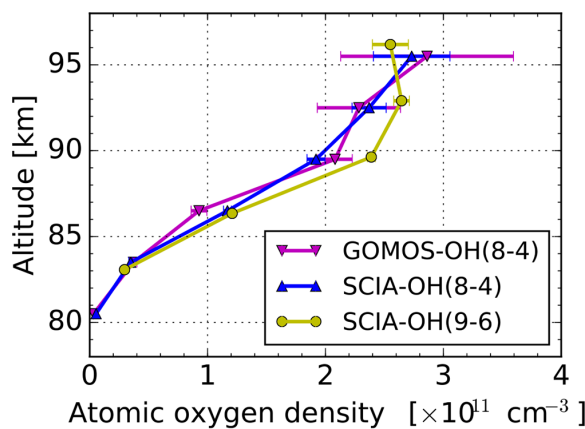

(d) $10^{\circ}-20^{\circ} \mathrm{S}$, Jul 2007

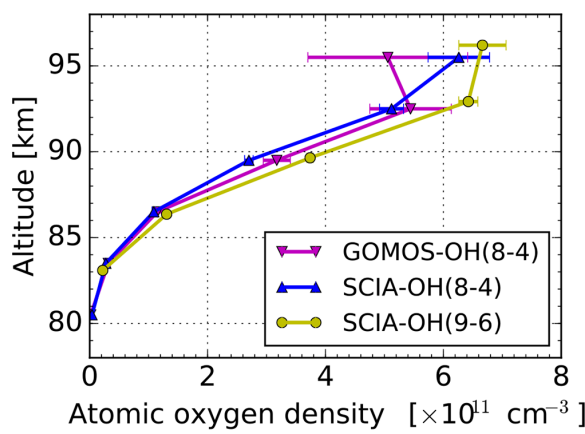

(f) $30^{\circ}-40^{\circ} \mathrm{N}$, Nov 2005

Figure 15. Comparison of monthly zonal mean atomic oxygen densities derived from hydroxyl airglow emissions observed by the GOMOS and SCIAMACHY instruments in various latitude bins for different months. SCIA-OH(9-6) represents the atomic oxygen dataset derived from the SCIAMACHY OH(9-6) band by Zhu and Kaufmann (2018); SCIA-OH(8-4) is the dataset from the SCIAMACHY OH(8-4) band; and GOMOS-OH(8-4) is from the GOMOS measurements of the $\mathrm{OH}(8-4)$ band.

be $10 \%-20 \%$ lower than those derived from $\mathrm{OH}(9-6)$ at around $90 \mathrm{~km}$. This might be explained by a slight underestimation of the quenching of $\mathrm{OH}(v=9)$ to $\mathrm{OH}(v=8)$ by $\mathrm{O}_{2}$, an overestimation of the deactivation of $\mathrm{OH}(v=8)$ due to collisions with atomic or molecular oxygen, or the over/underestimation of the branching factors $f_{9}$ and $f_{8}$ in the $\mathrm{OH}$ airglow model.

\subsection{Comparison with other datasets}

There are a number of $\mathrm{O}_{2}$ and $\mathrm{O}$ excited state emissions which can also be used to derive atomic oxygen. This includes $\mathrm{O}\left({ }^{1} \mathrm{~S}\right)$ green-line and $\mathrm{O}_{2}$ A-band emissions. Their modeling is mostly independent from the calculation of
$\mathrm{OH}(v)$ emissions, although some processes have to be considered in all models. Rocket-borne in situ measurements of atomic oxygen are the most independent from methods based on nightglow. Mostly performed in the 1970s (e.g., Dickinson et al., 1980; Sharp, 1980; Offermann et al., 1981), the measurements are very rare and selective in terms of the local time and location. Figure 16 gives an impression of how the various datasets of atomic oxygen available in the literature fit to each other. All the sets are selected using a similar local time of around 22:00-23:00 LT, with the exception of OSIRIS (18:30 LT) and in situ data with diverse local times at midnight or in the afternoon. 


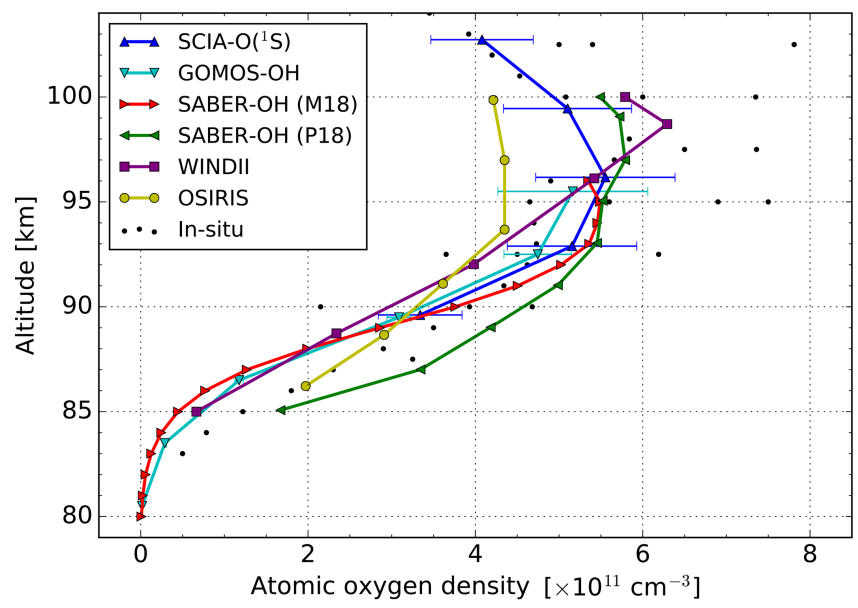

(a) $20^{\circ}-40^{\circ} \mathrm{N}$, Fall, 2005

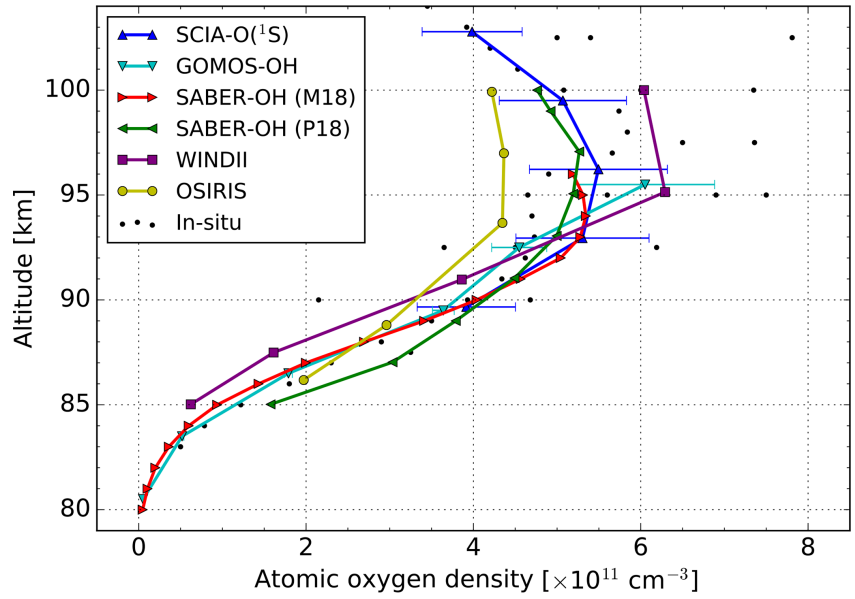

(b) $40^{\circ}-60^{\circ} \mathrm{N}$, Fall, 2005

Figure 16. Comparison of atomic oxygen densities derived from various instruments and measurement techniques averaged for 20 $40^{\circ} \mathrm{N}$ (a) and $40-60^{\circ} \mathrm{N}$ (b) in autumn (September, October and November) 2005. SCIA-O $\left({ }^{1} \mathrm{~S}\right)$ is the atomic oxygen data derived from SCIAMACHY green-line emissions (Kaufmann et al., 2014; Zhu et al., 2015); SABER-OH refers to the atomic oxygen datasets derived by Mlynczak et al. (2018) (M18), and Panka et al. (2018) (P18) from SABER hydroxyl airglow emissions. The WINDII dataset is obtained from WINDII combined hydroxyl and greenline observations, 1993 (Russell and Lowe, 2003; Russell et al., 2005), while the OSIRIS dataset is derived from OSIRIS $\mathrm{O}_{2}$ Aband measurements (Sheese et al., 2011). In situ data are obtained from rocket-borne experiments with mass spectrometers, conducted at different local times at $37-40^{\circ} \mathrm{N}$, from 1972 to 1976 (Offermann and Grossmann, 1973; Trinks et al., 1978; Offermann et al., 1981).

The datasets agree within their combined uncertainties in most cases. The absolute abundances are typically 4 $6 \times 10^{11}$ atoms $\mathrm{cm}^{-3}$ above $90 \mathrm{~km}$ and decrease with descending altitudes by 1 order of magnitude (at around $80 \mathrm{~km}$ ) for midlatitudes in autumn. GOMOS data are around $10 \%$ lower than SCIAMACHY-O $\left({ }^{1} \mathrm{~S}\right)$ and both SABER-OH datasets at $90-95 \mathrm{~km}$ but remain in good agreement with these datasets at lower altitudes below $90 \mathrm{~km}$. The OSIRIS dataset appears as the lower bound of the values above $90 \mathrm{~km}$, as it is always the lowest in this region, while it becomes relatively large below $90 \mathrm{~km}$. The WINDII dataset is around $10 \%$ lower than the GOMOS-OH data at an altitude of 87$92 \mathrm{~km}$, but they generally fit to each other. In situ data scatter in a large variation, which might be caused by the diurnal tides (local time differences), and the GOMOS-OH dataset is still located in its overall range of spread.

\section{Conclusions}

GOMOS limb observations of the background atmosphere provide the opportunity to retrieve atomic oxygen abundances from hydroxyl nightglow emissions at the mesopause. A global nighttime [O] dataset is obtained by applying the $\mathrm{OH}$ modeling and retrieval method to the monthly zonal mean of GOMOS limb measurements, with the atmospheric background profiles of temperature, total density and ozone taken from the SABER measurements. Its uncertainty comes from the measurement noise (around 5\%), selected relaxation schemes and kinetic parameters in $\mathrm{OH}$ modeling (contributing around $20 \%$ in total) and background atmosphere inputs, for example, atmospheric temperature and ozone (around $5 \%$ to $20 \%$ ). The obtained profiles present an overall picture of the vertical distribution of atomic oxygen from 80 to $100 \mathrm{~km}$. A temporal analysis of the profiles shows 11 year solar cycle effect tendencies as well as semiannual and annual variations, of which $\mathrm{SAO}$ is the most prominent.

The GOMOS data agree with the SCIAMACHY OH(8-4) measurements, with deviations typically smaller than $20 \%$. They are, on average, about 10\%-20\% lower than atomic oxygen data obtained from SCIAMACHY OH(9-6) observations. This might indicate that the collisional energy exchange between $\mathrm{OH}(v=9)$ and $\mathrm{OH}(v=8)$ via collisions with $\mathrm{O}_{2}$ and $\mathrm{O}$ in the $\mathrm{OH}$ airglow model requires some readjustments. Compared to other datasets derived from various instrument measurements, such as SABER, WINDII, OSIRIS and in situ rocket experiments, the GOMOS data also demonstrate an agreement with these datasets within their combined uncertainties.

Data availability. The GOMOS and SCIAMACHY data used in this study are available to the public at ftp://gomo-ftp-ds.eo.esa.int/ (last access: 1 November 2017) and ftp://scia-ftp-ds.eo.esa.int/ (last access: 1 November 2017) as part of the Cat-1 project 2515. SABER data version 2.0 can be downloaded from http://saber.gats-inc.com (last access: 10 February 2018). Derived atomic oxygen datasets are available upon request. 
Appendix A: Fitting of the selected collisional rate coefficients for $\mathrm{OH}(v=8)$

Some rate coefficients used in this work are obtained by simultaneously fitting the $\mathrm{OH}$ airglow model to measured limb radiances of $\mathrm{OH}(9-6)$ and $\mathrm{OH}(8-5)$ bands. The measurements are taken from SCIAMACHY channel-6 radiances. The $\mathrm{OH}(9-6)$ band radiance is integrated over the wavelength range of $1378-1404 \mathrm{~nm}$, and the $\mathrm{OH}(8-5)$ band is integrated over $1297-1326 \mathrm{~nm}$. The selected parameters are adjusted in such a way that the ratio between the simulated radiances of the two bands is consistent with the ratio obtained from the measurements. Several cases with different rate coefficients or combinations being adjusted in the fitting are considered, as given in Table A1. The fitting results of different cases are illustrated in the Fig. A1, as compared to the SCIAMACHY measurements. Model simulations of cases b, $\mathrm{c}$ and $\mathrm{d}$ have good agreement with the measurements. The rate coefficient for the collisional removal of $\mathrm{OH}(v=8)$ by the atomic oxygen differs from the literature by nearly 1 order of magnitude (Xu et al., 2012), and the fitted parameters should agree with the laboratory measurements within the combined uncertainties if available (Dyer et al., 1997). Therefore, case $b$ is chosen and applied in this work. The utilization of cases $\mathrm{c}$ and $\mathrm{d}$ will influence the retrieval results that atomic oxygen abundances will differ by around $5 \%$ above $90 \mathrm{~km}$ and $15 \%$ at $80 \mathrm{~km}$ compared to case b.

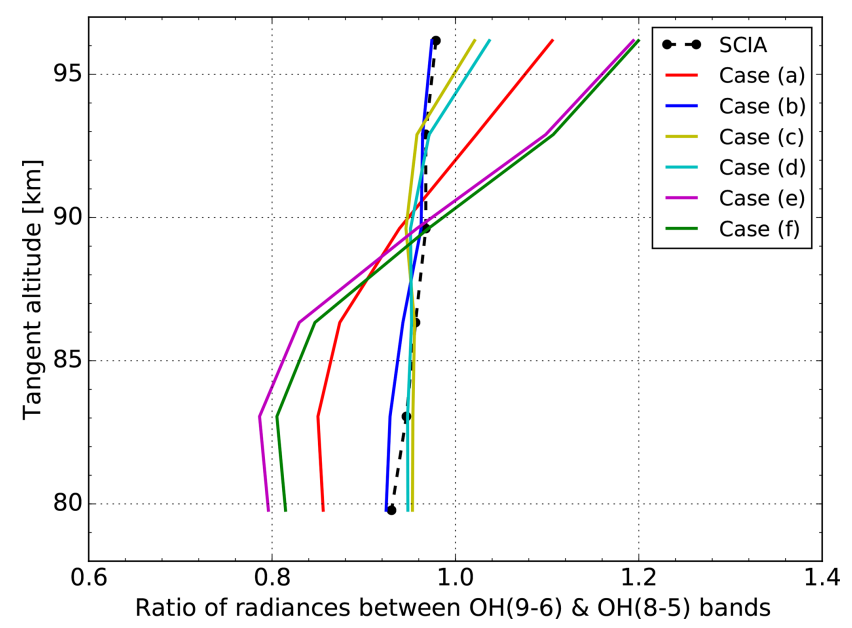

Figure A1. The ratio of the integrated limb radiances between the $\mathrm{OH}(9-6)$ (1378-1404 nm) and $\mathrm{OH}(8-5)$ (1297-1326 nm) bands versus tangent altitude. The raw data (black dashed line) are taken from the SCIAMACHY channel-6 measurements. The fitted results (solid line) are obtained by applying the rate coefficients with respect to different cases. 
Table A1. The comparison of study cases with the applied rate coefficients being summarized. The adjusted parameters and their fitted values are marked in bold, while the coefficients taken from laboratory measurements are marked in italic.

\begin{tabular}{lrrrr}
\hline Study case & $k_{\mathrm{O}(8)} \times 10^{-10} \mathrm{~cm}^{3} \mathrm{~s}^{-1}$ & $k_{\mathrm{O}_{2}(8)} \times 10^{-12} \mathrm{~cm}^{3} \mathrm{~s}^{-1}$ & $k_{\mathrm{N}_{2}(8)} \times 10^{-13} \mathrm{~cm}^{3} \mathrm{~s}^{-1}$ & $k_{\mathrm{O}_{2}(9,8)} \times 10^{-13} \mathrm{~cm}^{3} \mathrm{~s}^{-1}$ \\
\hline a & $\mathbf{1 . 2}$ & 8.0 & 7.0 & 42.0 \\
$\mathrm{~b}$ & $\mathbf{0 . 6 5}$ & 8.0 & 7.0 & $\mathbf{8 . 9}$ \\
$\mathrm{c}$ & $\mathbf{0 . 2 5}$ & $\mathbf{1 2 . 0}$ & 7.0 & 42.0 \\
$\mathrm{~d}$ & $\mathbf{0 . 3 5}$ & 8.0 & $\mathbf{1 5 . 0}$ & 42.0 \\
$\mathrm{e}$ & 2.0 & $\mathbf{5 . 5}$ & 7.0 & 42.0 \\
$\mathrm{f}$ & 2.0 & 8.0 & $\mathbf{4 . 5}$ & 42.0 \\
\hline
\end{tabular}


Author contributions. QC processed the data, performed the analysis and drafted the manuscript. MK and YZ initiated the topic, provided insight and instructions, and discussed the results regularly. All authors contributed to the revision and improvement of the paper.

Competing interests. The authors declare that they have no conflict of interest.

Acknowledgements. Qiuyu Chen was supported in her work by the China Scholarship Council. The work of Yajun Zhu was supported by the 2017 Helmholtz-OCPC Programme and the International Postdoctoral Exchange Fellowship Program 2017. We also thank three anonymous referees for their valuable comments and suggestions.

Financial support. The article processing charges for this openaccess publication were covered by a Research Centre of the Helmholtz Association.

Review statement. This paper was edited by William Ward and reviewed by three anonymous referees.

\section{References}

Adler-Golden, S.: Kinetic parameters for $\mathrm{OH}$ nightglow modeling consistent with recent laboratory measurements, J. Geophys. Res.-Space Phys., 102, 19969-19976, https://doi.org/10.1029/97JA01622, 1997.

Baker, D., Pendleton Jr., W., Steed, A., Huppi, R., and Stair Jr., A. T.: Near-infrared spectrum of an aurora, Geophys. Res. Lett., 82, 1601-1609, https://doi.org/10.1029/JA082i010p01601, 1977.

Barrot, G., Bertaux, J.-L., Fraisse, R., and Mangin, A.: GOMOS calibration on Envisat-status on December 2002, in: Proc. of Envisat Validation Workshop, 2003.

Bellisario, C., Keckhut, P., Blanot, L., Hauchecorne, A., and Simoneau, P.: $\mathrm{O}_{2}$ and $\mathrm{OH}$ night airglow emission derived from GOMOS-Envisat instrument, J. Atmos. Ocean. Tech., 31, 13011311, https://doi.org/10.1175/JTECH-D-13-00135.1, 2014.

Bovensmann, H., Burrows, J. P., Buchwitz, M., Frerick, J., Noël, S., Rozanov, V. V., Chance, K. V., and Goede, A. P. H.: SCIAMACHY: Mission objectives and measurement modes, J. Atmos. Sci., 56, 127-150, https://doi.org/10.1175/15200469(1999)056<0127:SMOAMM>2.0.CO;2, 1999.

Bramstedt, K., Noël, S., Bovensmann, H., Burrows, J. P., Lerot, C., Tilstra, L., Lichtenberg, G., Dehn, A., and Fehr, T.: SCIAMACHY monitoring factors: Observation and end-to-end correction of instrument performance degradation, in: Proceedings of Atmospheric Science Conference, European space agency, Barcelona, Spain, 2009.

Brasseur, G. and Offermann, D.: Recombination of atomic oxygen near the mesopause: Interpretation of rocket data, J. Geophys. Res.-Atmos., 91, 10818-10824, https://doi.org/10.1029/JD091iD10p10818, 1986.

Brasseur, G. P. and Solomon, S.: Aeronomy of the middle atmosphere: Chemistry and physics of the stratosphere and mesosphere, in: Atmospheric and Oceanographic Sciences Library, 3 edn., Springer, Netherlands, 2005.

Dawkins, E. C. M., Feofilov, A., Rezac, L., Kutepov, A. A., Janches, D., Höffner, J., Chu, X., Lu, X., Mlynczak, M. G., and Russell III, J.: Validation of SABER v2.0 operational temperature data with ground-based lidars in the Mesosphere-Lower Thermosphere Region (75-105 km), J. Geophys. Res.-Atmos., 123, 9916-9934, https://doi.org/10.1029/2018JD028742, 2018.

Dehn, A.: Quality readme file for GOMOS level $1 \mathrm{~b}$ data version GOMOS/6.01, Tech. Rep. ENVI-GSOP-EOGD-QD-12-0116, European Space Agency, 2012.

de Wit, R. J., Hibbins, R. E., Espy, P. J., and Mitchell, N. J.: Interannual variability of mesopause zonal winds over Ascension Island: Coupling to the stratospheric QBO, J. Geophys. Res.-Atmos., 118, 12052-12060, https://doi.org/10.1002/2013JD020203, 2013.

Dickinson, P. H. G., Bolden, R. C., and Young, R. A.: Measurement of atomic oxygen in the lower ionosphere using a rocket-borne resonance lamp, Nature, 252, 289-291, https://doi.org/10.1038/252289a0, 1974.

Dickinson, P. H. G., Bain, W. C., Thomas, L., Williams, E. R., Jenkins, D. B., and Twiddy, N. D.: The determination of the atomic oxygen concentration and associated parameters in the lower ionosphere, Philos. T. R. Soc. S-A, 369, 379-408, 1980.

Dyer, M. J., Knutsen, K., and Copeland, R. A.: Energy transfer in the ground state of $\mathrm{OH}$ : Measurements of $\mathrm{OH}(v=8,10,11)$ removal, J. Chem. Phys., 107, 7809-7815, https://doi.org/10.1063/1.475094, 1997.

ESA: European space agency-Envisat GOMOS Product Handbook, http://envisat.esa.int/handbooks/gomos/CNTR.html (last access: 8 November 2016), 2010.

Fytterer, T., von Savigny, C., Mlynczak, M., and Sinnhuber, M.: Model results of $\mathrm{OH}$ airglow considering four different wavelength regions to derive night-time atomic oxygen and atomic hydrogen in the mesopause region, Atmos. Chem. Phys., 19, 18351851, https://doi.org/10.5194/acp-19-1835-2019, 2019.

Gao, H., Nee, J.-B., and Xu, J.: The emission of oxygen green line and density of $\mathrm{O}$ atom determined by using ISUAL and SABER measurements, Ann. Geophys., 30, 695-701, https://doi.org/10.5194/angeo-30-695-2012, 2012.

Gottwald, M., Diekmann, F.-J., and Fehr, T.: ENVISAT - SCIAMACHY's Host, in: SCIAMACHY - Exploring the Changing Earth's Atmosphere, XVI, 225, Springer, Netherlands, https://doi.org/10.1007/978-90-481-9896-2, 2011.

Hays, P. B., Abreu, V. J., Dobbs, M. E., Gell, D. A., Grassl, H. J., and Skinner, W. R.: The high-resolution doppler imager on the Upper Atmosphere Research Satellite, J. Geophys. Res.-Atmos., 98, 10713-10723, https://doi.org/10.1029/93JD00409, 1993.

Kalogerakis, K. S.: A previously unrecognized source of the $\mathrm{O}_{2}$ Atmospheric band emission in Earth's nightglow, Sci. Adv., 5, 3, https://doi.org/10.1126/sciadv.aau9255, 2019.

Kalogerakis, K. S., Smith, G. P., and Copeland, R. A.: Collisional removal of $\mathrm{OH}\left(\mathrm{X} 2 \prod, v=9\right)$ by $\mathrm{O}, \mathrm{O}_{2}$, $\mathrm{O}_{3}, \mathrm{~N}_{2}$, and $\mathrm{CO}_{2}$, J. Geophys. Res.-Atmos., 116, D20, https://doi.org/10.1029/2011JD015734, 2011. 
Kalogerakis, K. S., Matsiev, D., Sharma, R. D., and Wintersteiner, P. P.: Resolving the mesospheric nighttime $4.3 \mu \mathrm{m}$ emission puzzle: Laboratory demonstration of new mechanism for $\mathrm{OH}(v)$ relaxation, Geophys. Res. Lett., 43, 8835-8843, https://doi.org/10.1002/2016GL069645, 2016.

Kaufmann, M., Lehmann, C., Hoffmann, L., Funke, B., LópezPuertas, M., Savigny, C., and Riese, M.: Chemical heating rates derived from SCIAMACHY vibrationally excited OH limb emission spectra, Adv. Space Res., 41, 1914-1920, https://doi.org/10.1016/j.asr.2007.07.045, 2008.

Kaufmann, M., Ern, M., Lehmann, C., and Riese, M.: The response of atomic hydrogen to solar radiation changes, in: Climate And Weather of the Sun-Earth System (CAWSES): Highlights from a priority program, pp. 171-188, Springer Atmospheric Sciences, Dordrecht, 2013.

Kaufmann, M., Zhu, Y., Ern, M., and Riese, M.: Global distribution of atomic oxygen in the mesopause region as derived from SCIAMACHY O $\left({ }^{1} \mathrm{~S}\right)$ green line measurements, Geophys. Res. Lett., 41, 6274-6280, https://doi.org/10.1002/2014GL060574, 2014.

Kyrölä, E., Tamminen, J., Sofieva, V., Bertaux, J. L., Hauchecorne, A., Dalaudier, F., Fussen, D., Vanhellemont, F., Fanton d'Andon, O., Barrot, G., Guirlet, M., Mangin, A., Blanot, L., Fehr, T., Saavedra de Miguel, L., and Fraisse, R.: Retrieval of atmospheric parameters from GOMOS data, Atmos. Chem. Phys., 10, 1188111903, https://doi.org/10.5194/acp-10-11881-2010, 2010.

Kyrölä, E., Blanot, L., Tamminen, J., Sofieva, V., Bertaux, J. L., Hauchecorne, A., Dalaudier, F., Fussen, D., Vanhellemont, F., d'Andon, O. F., and Barrot, G.: Algorithm theoretical basis document version 3.0, Tech. Rep. GOM-FMI-TN-040, Finnish Meteorological Institute and ACRI-ST and LATMOS-IPSL and Institut d'Aéronomie Spatiale de Belgique, 2012.

Lacoursiére, J., Dyer, M. J., and Copeland, R. A.: Temperature dependence of the collisional energy transfer of $\mathrm{OH}(v=10)$ between 220 and $310 \mathrm{~K}$, J. Chem. Phys., 118, 1661-1666, https://doi.org/10.1063/1.1530581, 2003.

Lednyts'kyy, O., von Savigny, C., Eichmann, K.-U., and Mlynczak, M. G.: Atomic oxygen retrievals in the MLT region from SCIAMACHY nightglow limb measurements, Atmos. Meas. Tech., 8, 1021-1041, https://doi.org/10.5194/amt-8-1021-2015, 2015.

Lednyts'kyy, O., von Savigny, C., and Weber, M.: Sensitivity of equatorial atomic oxygen in the MLT region to the 11-year and 27-day solar cycles, J. Atmos. Sol.-Terr. Phys., 162, 136-150, https://doi.org/10.1016/j.jastp.2016.11.003, 2017.

Li, F., Liu, A. Z., and Swenson, G. R.: Characteristics of instabilities in the mesopause region over Maui, Hawaii, J. Geophys. Res.Atmos., 110, D9, https://doi.org/10.1029/2004JD005097, 2005.

Malhotra, G., Ruohoniemi, J. M., Baker, J. B. H., Hibbins, R. E., and McWilliams, K. A.: HF radar observations of a quasi-biennial oscillation in midlatitude mesospheric winds, J. Geophys. Res.-Atmos., 121, 12677-12689, https://doi.org/10.1002/2016JD024935, 2016.

Marsh, D. R., Garcia, R. R., Kinnison, D. E., Boville, B. A., Sassi, F., Solomon, S. C., and Matthes, K.: Modeling the whole atmosphere response to solar cycle changes in radiative and geomagnetic forcing, J. Geophys. Res.-Atmos., 112, d23306, https://doi.org/10.1029/2006JD008306, 2007.

Massimo Cardaci, R. and Lannone, Q.: ENVISAT-1 products specifications - Volume 10:GOMOS products specifications, Tech.
Rep. PO-RS-MDA-GS-2009/IDEAS-SER-IPF-SPE-1124, Serco SpA, 2012.

Mlynczak, M. G., Hunt, L. A., Marshall, B. T., Mertens, C. J., Russell, J. M., Siskind, D., Thompson, R. E., and Gordley, L. L.: Radiative constraints on the minimum atomic oxygen concentration in the mesopause region, Geophys. Res. Lett., 40, 3777-3780, https://doi.org/10.1002/grl.50725, 2013a.

Mlynczak, M. G., Hunt, L. A., Mast, J. C., Thomas Marshall, B., Russell, J. M., Smith, A. K., Siskind, D. E., Yee, J.-H., Mertens, C. J., Javier Martin-Torres, F., Earl Thompson, R., Drob, D. P., and Gordley, L. L.: Atomic oxygen in the mesosphere and lower thermosphere derived from SABER: Algorithm theoretical basis and measurement uncertainty, J. Geophys. Res.-Atmos., 118, 5724-5735, https://doi.org/10.1002/jgrd.50401, 2013 b.

Mlynczak, M. G., Hunt, L. H., Mertens, C. J., Marshall, B. T., Russell, J. M., López Puertas, M., Smith, A. K., Siskind, D. E., Mast, J. C., Thompson, R. E., and Gordley, L. L.: Radiative and energetic constraints on the global annual mean atomic oxygen concentration in the mesopause region, J. Geophys. Res.-Atmos., 118, 5796-5802, https://doi.org/10.1002/jgrd.50400, 2013c.

Mlynczak, M. G., Hunt, L. A., Russell, J. M., and Marshall, B. T.: Updated SABER night atomic oxygen and implications for SABER ozone and atomic hydrogen, Geophys. Res. Lett., 45, 5735-5741, https://doi.org/10.1029/2018GL077377, 2018.

Offermann, D. and Grossmann, K. U.: Thermospheric density and composition as determined by a mass spectrometer with cryo ion source, J. Geophys. Res., 78, 8296-8304, https://doi.org/10.1029/JA078i034p08296, 1973.

Offermann, D., Friedrich, V., Ross, P., and Zahn, U. V.: Neutral gas composition measurements between 80 and $120 \mathrm{~km}$, Planet. Space Sci., 29, 747-764, https://doi.org/10.1016/00320633(81)90046-5, 1981.

Panka, P. A., Kutepov, A. A., Kalogerakis, K. S., Janches, D., Russell, J. M., Rezac, L., Feofilov, A. G., Mlynczak, M. G., and Yiğit, E.: Resolving the mesospheric nighttime $4.3 \mu \mathrm{m}$ emission puzzle: comparison of the $\mathrm{CO}_{2}\left(v_{3}\right)$ and $\mathrm{OH}(v)$ emission models, Atmos. Chem. Phys., 17, 9751-9760, https://doi.org/10.5194/acp17-9751-2017, 2017.

Panka, P. A., Kutepov, A. A., Rezac, L., Kalogerakis, K. S., Feofilov, A. G., Marsh, D., Janches, D., and Yiğit, E.: Atomic oxygen retrieved from the SABER 2.0- and 1.6- $\mu$ m radiances using new first-principles nighttime $\mathrm{OH}(\mathrm{v})$ model, Geophys. Res. Lett., 45, 5798-5803, https://doi.org/10.1029/2018GL077677, 2018.

Picone, J. M., Hedin, A. E., Drob, D. P., and Aikin, A. C.: NRLMSISE-00 empirical model of the atmosphere: Statistical comparisons and scientific issues, J. Geophys. Res.-Space, 107, 15-16, https://doi.org/10.1029/2002JA009430, 2002.

Ratnam, M. V., Kumar, G. K., Murthy, B. V. K., Patra, A. K., Rao, V. V. M. J., Rao, S. V. B., Kumar, K. K., and Ramkumar, G.: Long-term variability of the low latitude mesospheric SAO and QBO and their relation with stratospheric QBO, Geophys. Res. Lett., 35, 21, https://doi.org/10.1029/2008GL035390, 2008.

Riese, M., Offermann, D., and Brasseur, G.: Energy released by recombination of atomic oxygen and related species at mesopause heights, J. Geophys. Res.-Atmos., 99, 14585-14593, https://doi.org/10.1029/94JD00356, 1994.

Rodgers, C. D.: Inverse methods for atmospheric sounding:theory and practice, World Scientific, Singapore, 2000. 
Russell, J. P. and Lowe, R. P.: Atomic oxygen profiles (80-94 km) derived from Wind Imaging Interferometer/Upper Atmospheric Research Satellite measurements of the hydroxyl airglow: 1. Validation of technique, J. Geophys. Res.-Atmos., 108, 4662, https://doi.org/10.1029/2003JD003454, 2003.

Russell, J. P., Ward, W. E., Lowe, R. P., Roble, R. G., Shepherd, G. G., and Solheim, B.: Atomic oxygen profiles (80 to $115 \mathrm{~km}$ ) derived from Wind Imaging Interferometer/Upper Atmospheric Research Satellite measurements of the hydroxyl and greenline airglow: Local time-latitude dependence, J. Geophys. Res.Atmos., 110, D15, https://doi.org/10.1029/2004JD005570, 2005.

Sander, S., Abbatt, J., Barker, J., Burkholder, J., Friedl, R., Golden, D., Huie, R., Kurylo, M., Moortgat, G., Orkin, V., and Wine, P.: Chemical kinetics and photochemical data for use in atmospheric studies, evaluation No. 17, Tech. rep., Jet Propulsion Laboratory, California Institute of Technology, Pasadena, CA, 2011.

Schmidt, H., Brasseur, G. P., Charron, M., Manzini, E., Giorgetta, M. A., Diehl, T., Fomichev, V. I., Kinnison, D., Marsh, D., and Walters, S.: The HAMMONIA chemistry climate model: Sensitivity of the mesopause region to the 11-Year solar cycle and $\mathrm{CO}_{2}$ doubling, J. Climate, 19, 3903-3931, https://doi.org/10.1175/JCLI3829.1, 2006.

Sharma, R. D., Wintersteiner, P. P., and Kalogerakis, K. S.: A new mechanism for $\mathrm{OH}$ vibrational relaxation leading to enhanced $\mathrm{CO}_{2}$ emissions in the nocturnal mesosphere, Geophys. Res. Lett., 42, 4639-4647, https://doi.org/10.1002/2015GL063724, 2015.

Sharp, W. E.: Absolute concentrations of $\mathrm{O}\left({ }^{3} \mathrm{P}\right)$ in the lower thermosphere at night, Geophys. Res. Lett., 7, 485-488, https://doi.org/10.1029/GL007i007p00485, 1980.

Sharp, W. E.: The measurement of atomic oxygen in the mesosphere and lower thermosphere, Planet. Space Sci., 39, 617-626, 1991.

Sheese, P. E., McDade, I. C., Gattinger, R. L., and Llewellyn, E. J.: Atomic oxygen densities retrieved from Optical Spectrograph and Infrared Imaging System observations of $\mathrm{O}_{2} \mathrm{~A}$-band airglow emission in the mesosphere and lower thermosphere, J. Geophys. Res.-Atmos., 116, D1, https://doi.org/10.1029/2010JD014640, 2011.

Sheese, P. E., Llewellyn, E. J., Gattinger, R. L., and Strong, K.: OH Meinel band nightglow profiles from OSIRIS observations, J. Geophys. Res.-Atmos., 119, 11417-11428, https://doi.org/10.1002/2014JD021617, 2014.

Smith, A. K., Marsh, D. R., Mlynczak, M. G., and Mast, J. C.: Temporal variations of atomic oxygen in the upper mesosphere from SABER, J. Geophys. Res.-Atmos., 115, D18, https://doi.org/10.1029/2009JD013434, 2010.

Smith, S. A., Fritts, D. C., and Vanzandt, T. E.: Evidence for a saturated spectrum of atmospheric gravity waves, J. Atmos. Sci., 44, 1404-1410, https://doi.org/10.1175/15200469(1987)044<1404:EFASSO>2.0.CO;2, 1987.
Swenson, G., Yee, Y., Vargas, F., and Liu, A.: Vertical diffusion transport of atomic oxygen in the mesopause region consistent with chemical losses and continuity: Global mean and inter-annual variability, J. Atmos. Sol.-Terr. Phys., 178, 47-57, https://doi.org/10.1016/j.jastp.2018.05.014, 2018.

Tapping, K. F.: The $10.7 \mathrm{~cm}$ solar radio flux (F10.7), Space Weather, 11, 394-406, https://doi.org/10.1002/swe.20064, 2013.

Thomas, R. J.: Atomic hydrogen and atomic oxygen density in the mesopause region: Global and seasonal variations deduced from Solar Mesosphere Explorer near-infrared emissions, J. Geophys. Res.-Atmos., 95, 16457-16476, https://doi.org/10.1029/JD095iD10p16457, 1990.

Tikhonov, A. and Arsenin, V.: Solutions of ill-posed problems, Scripta series in mathematics, Winston, Washington D.C., USA, 1977.

Trinks, H., Offermann, D., von Zahn, U., and Steinhauer, C.: Neutral composition measurements between 90- and 220-km altitude by rocket-borne mass spectrometer, J. Geophys. Res., 83, 2169 2176, https://doi.org/10.1029/JA083iA05p02169, 1978.

van Gijsel, J. A. E., Swart, D. P. J., Baray, J.-L., Bencherif, H., Claude, H., Fehr, T., Godin-Beekmann, S., Hansen, G. H., Keckhut, P., Leblanc, T., McDermid, I. S., Meijer, Y. J., Nakane, H., Quel, E. J., Stebel, K., Steinbrecht, W., Strawbridge, K. B., Tatarov, B. I., and Wolfram, E. A.: GOMOS ozone profile validation using ground-based and balloon sonde measurements, Atmos. Chem. Phys., 10, 10473-10488, https://doi.org/10.5194/acp-10-10473-2010, 2010.

Xu, J., Smith, A. K., Jiang, G., Gao, H., Wei, Y., Mlynczak, M. G., and Russell III, J. M.: Strong longitudinal variations in the $\mathrm{OH}$ nightglow, Geophys. Res. Lett., 37, 21, https://doi.org/10.1029/2010GL043972, 2010.

Xu, J., Gao, H., Smith, A. K., and Zhu, Y.: Using TIMED/SABER nightglow observations to investigate hydroxyl emission mechanisms in the mesopause region, J. Geophys. Res.-Atmos., 117, D2, https://doi.org/10.1029/2011JD016342, 2012.

Zhu, Y. and Kaufmann, M.: Atomic oxygen abundance retrieved from SCIAMACHY hydroxyl nightglow measurements, Geophys. Res. Lett., 45, 9314-9322, https://doi.org/10.1029/2018GL079259, 2018.

Zhu, Y., Kaufmann, M., Ern, M., and Riese, M.: Nighttime atomic oxygen in the mesopause region retrieved from SCIA$\left.\mathrm{MACHY} O{ }^{1} \mathrm{~S}\right)$ green line measurements and its response to solar cycle variation, J. Geophys. Res.-Space, 120, 9057-9073, https://doi.org/10.1002/2015JA021405, 2015. 